\title{
Process Water Recirculation During Hydrothermal Carbonization as a Promising Process Step Towards the Production of Nitrogen-Doped Carbonaceous Materials
}

\author{
Wüst Dominik ${ }^{1,2} \mathbb{D} \cdot$ Arauzo Pablo $^{2} \cdot$ Habicht Sonja $^{3} \cdot$ Cazaña Fernando $^{4} \cdot$ Fiori Luca $^{1} \cdot$ Kruse Andrea $^{2}$
}

Received: 10 February 2021 / Accepted: 6 October 2021 / Published online: 25 November 2021

(c) The Author(s) 2021

\begin{abstract}
Hydrothermal Carbonization (HTC) refers to the conversion of biogenic wastes into char-like solids with promising perspectives for application, but a process water (PW) results which is difficult to dispose untreated. Thus, a biorefinery approach including one or two recirculation steps with the additional objective of improving the physico-chemical characteristics of the solid was performed in this study. During HTC, constitutive molecules such as saccharides, proteins and lignin of Brewer's Spent Grains decompose into hundreds of organic compounds, following complex reactions. To get deeper insights a combination of proximate, ultimate and structural analysis for solid products as well as liquid chromatography for liquid products were the choice. The main reactions could be identified by key compounds of low and high molecular weight resulting from hydrolysis, dehydration, decarboxylation, deamination as well as amide formation and condensation reactions. Their intensity was influenced by the feedwater $\mathrm{pH}$ and reaction temperature. Via reactions of Maillard character up to around $90 \%$ of the dissolved nitrogen of the recirculated process water at 200,220 and $240{ }^{\circ} \mathrm{C}$ result in the formation of nitrogen containing heterocycles or rather Quartnernary nitrogen incorporated into the hydrochar (HC). Thus, already one recirculation step during $\mathrm{HTC}$ at $240{ }^{\circ} \mathrm{C}$ promises the fabrication of high added-value materials, i.e. nitrogen doped carbonaceous materials.
\end{abstract}

\section{Graphic Abstract}

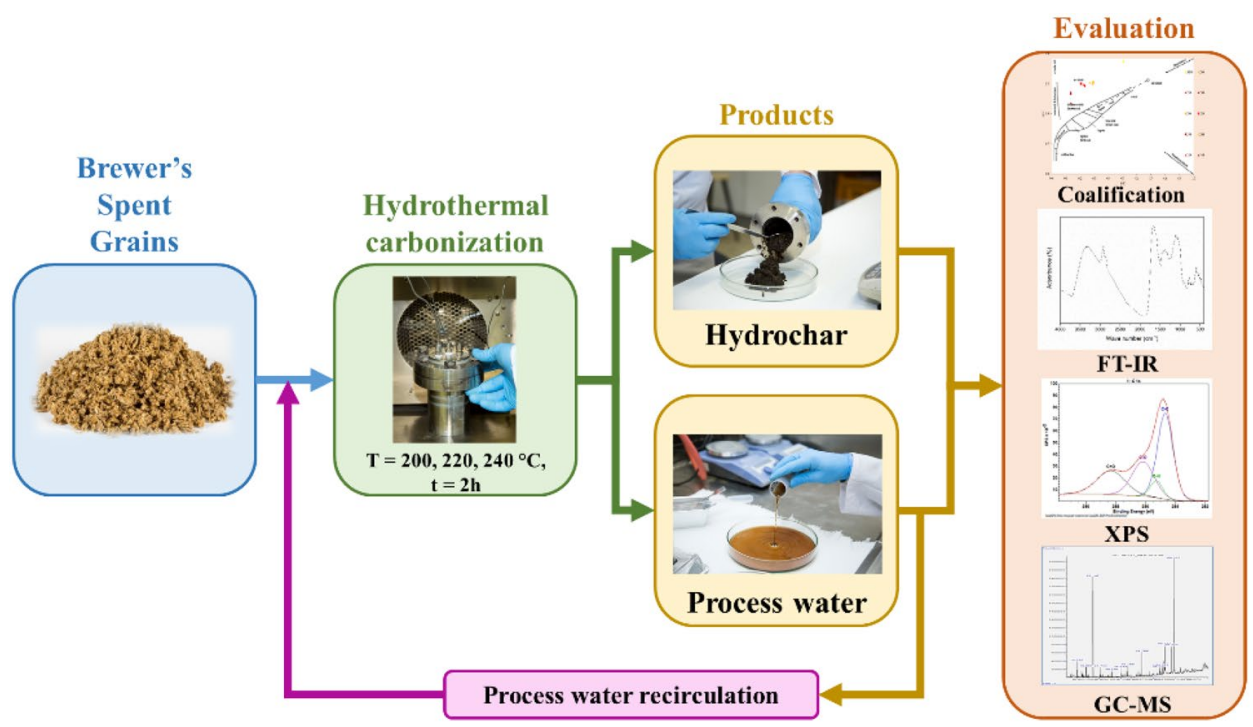

Keywords Bioeconomy $\cdot$ Biorefinery $\cdot$ Hydrothermal Carbonization $\cdot$ Process water recirculation $\cdot$ Maillard reaction · Nitrogen-doped carbonaceous materials

Extended author information available on the last page of the article 


\section{Statement of Novelty}

The main objectives of this research were to investigate the effectiveness of process water recirculation as wastewater management technique during Hydrothermal Carbonization (HTC) of a saccharide- and protein-rich soft-lignocellulosic feedstock as well as to identify the key reactions as the determining factors for the production of tailored-char. Maillard reactions promoted by the reaction temperature and the feedwater character played a crucial role in obtaining a solid product with improved physicochemical characteristics. For the future, this study provides a basis for putting concepts concerning the production of hydrochar as energy carrier or precursor for e.g. electrode materials in supercapacitors including waste management into practise.

\section{Introduction}

In 1913, Bergius [1] reported a thermochemical process that imitates the natural coalification within a few hours, which is termed hydothermal carbonization (HTC) now. In 2007, at the Max Planck Institute of Colloids and Interfaces, HTC was rediscovered as an alternative process for the production of modern carbon materials for different kind of applications, firstly using saccharides as initial feedstock [2]. Nowadays, HTC is developed by several companies as a technology for processing residues in continous (tubular) and quasi-continuous (multi-batch) reactors. Due to their pumpability, biogenic wastes from agriculture, municipality and food industry with moisture contents between 70 and $90 \%$ can be processed [3]. As the pumpability is a decisive feature for the automatization, the external supply of water is frequently applied. In addition, this enhances the homogenization and the heat exchange during the HTC process. In most studies fresh water is used, but also, like here, the aqueous phase of a previous HTC run can be recycled.

In this industrial context, one of the main bottlenecks associated with HTC concerns the water consumption, which has a negative effect on ecological and social sustainability [4]. After the HTC process, an aqueous phase is obtained, which is termed process water $(\mathrm{PW})$. It is necessary to develop approaches to reduce the water consumption. PW has usually a high total organic carbon content (TOC) and correspondingly a high chemical oxygen demand (COD) [5].

In addition to the reduction of the water consumption, a sustainable disposal or recycling method of the PW is necessary. This is not an easy task due to complex and diverse composition of the organic compounds in PW. It depends on the matrix complexity of biogenic feedstock considering the carbohydrates (oligo-, poly-, tri-, di- and monosaccharides), proteins, lipids and inorganics as well as HTC reaction conditions.

The reactivity of biomass during hydrolyis varies. At temperatures over $220{ }^{\circ} \mathrm{C}$ and residence times longer than 120 min the structure of lignocellulosic biomass such as Brewer's Spent Grains (BSG) is mostly degraded and its intial carbon bound is dissolved as organic compounds in the PW, or consecutively forms secondary char. For such biomass, the formation of secondary char dominates compared to the reaction via intramolecular condensation and decarboxylation to primary char [6]. This is different for lignocellulosic biomass with a more stable structure, for which primary char formation is much more important [7].

According to waste water regulations, the PW needs a previous treatment, before its deposition to the sewage system. Consequently, a disposal company has to be engaged, which is expensive, considering the percentage of organics in the PW of up to $20 \%$ of the carbon input [8]. As an approach, several studies have been carried out with PW for example as a feedstock for anaerobic digestion [9-13], wet oxidation [14, 15] and algae cultivation [16]. Furthermore, researchers investigated the PW recirculation in HTC of poplar wood [17], grape pomace [18], sawdust [19], loblolly pine [20], miscanthus [21], sweet potato waste [22] and BSG $[6,23]$. Although, the effect of the PW recirculation on the characteristics of hydrochars (HCs) was somehow inconsistent with each other, the previous studies conclude that PW recirculation increased the $\mathrm{HC}$ yield and the carbon retention efficiency. In addition, the HHV and the Dissolved Organic Carbon (DOC) of the resulting PW is reduced.

Wüst et al. found that the higher the concentrations of reactive organic compounds such as (reducing) saccharides and Furfural-like compounds in the recirculable PW, the higher the HC yield and carbon retention efficiency [6]. This is a consequence of the increased support of secondary char formation. While Wüst et al. described the formation of the carbohydrate-originated products [6], Becker et al. studied the formation of lipid- and lignin-originated products [5] and Zhuang et al. investigated the formation of proteinoriginated products of HTC with PW recirculation [24, 25]. Two studies have been published so far that also adressed the reaction pathways in the reaction medium more in detail, with respect to the physicochemical characteristics of the obtained HCs [26, 27].

In case $\mathrm{PW}$ is reused for dispersion of biomass, reaction between organic compounds in the PW with compounds formed from the biomass can occur. When these compounds originate from carbohydrates, the products of polymerisation is called secondary char [28]. The Maillard reactions occurs between carbohydrate and protein degradation products and leads to nitrogen containing heterocyclic rings [29]. 
These nitrogen containing compounds can be found in solution, or via polymerization in the solid phase [30], termed nitrogen doped carbonaceous material here. Lipids could be hydrolysed, while the resulting fatty acids may decarboxylate rather than degraded below $300{ }^{\circ} \mathrm{C}$ [31]. Finally, they condensate and form an oily phase of the solid product. Usually lignin is only hydrolyzed to a minor extent, at HTC conditions [32]. In case of PW recirculation, lignin oligomers or other compounds including phenols, may hydrolyse because of the higher over-all reactions time. Now the question occurs, whether they can take part in polymerization reactions and form char.

To understand these processes, and to be able to produce tailored-chars with a low amount of oxygen- and nitrogencontaining surface functional groups and correspondingly a lower electrical resistance in the future [33], the solid and the liquid phase are analysed. In this context a suitable tool is the PW recirculation, which results in promotion of the relevant reactions such as depolymerization, deoxygenation, dehydration, decarboxylation as well as dimerization and cyclization [34-36]. It has to be considered that longchain intermediates and products will be found in the solid, but their shorter chain precursors are in the liquid phase. Therefore, a detailed analysis of the liquid and the solid phase is necessary, which was not completely possible. However, the focus was on the identification and analysis of key compounds, indicating specific reactions between compounds originated from lipids and proteins together with those of carbohydrates.

\section{Material and Methods}

\section{Brewer's Spent Grains (BSG)}

BSG (Privatbrauerei Hoepfner, Karlsruhe, Germany) with a dry matter content of 28 wt. \% was used untreated. It is composed of the particle size fractions $0-250 \mu \mathrm{m}$ with $6 \%$, 250-500 $\mu \mathrm{m}$ with $9 \%, 500-1000 \mu \mathrm{m}$ with $23 \%$ and larger than $1000 \mu \mathrm{m}$ with $61 \%$. Table 1 shows that it distincly differs by a $13 \%$ higher hemicellulose and by $5.2 \%$ higher lignin content (see Table 1) in comparison to that one used by Wüst et al. [6]. Contrary to this previous study, the content of inorganic carbonates with $0.7 \%(\approx 0.146 \mathrm{C} \%)$ (see Eq. 10) has to be considered for the calculations of carbon retention efficiency $\left(\mathrm{C}_{\text {eff }}\right)$. The biochemical, chemical and physical characteristics differ by a maximum of $\pm 5 \%$ in both studies, which consequently has an influence on the atomic ratios. The reason is a variation of the basis (barley, wheat), which depends on the recipe of beer types and their brewing process [37, 38].
Table 1 Physico- and biochemical analysis of Brewer's Spent Grains on a dry basis

\begin{tabular}{|c|c|c|c|c|c|}
\hline \multicolumn{6}{|c|}{ Biochemical characteristics } \\
\hline Crude fibre & $\mathrm{ADL}^{[\mathrm{c}] / \text { Lignin }}$ & Hemicellulose ${ }^{[\mathrm{d}]}$ & Cellulose ${ }^{[\mathrm{d}]}$ & Crude fat & Crude protein ${ }^{\mathrm{e}]}$ \\
\hline \multicolumn{6}{|l|}{ [wt.\%] } \\
\hline 17.3 & 12.0 & 40.6 & 23.2 & 4.9 & 23.4 \\
\hline \multicolumn{6}{|c|}{ Chemical characteristics } \\
\hline $\begin{array}{l}\mathrm{C}_{\text {org }}{ }^{[\mathrm{f}]} \\
\text { [wt.\%] }\end{array}$ & $\mathrm{H}$ & $\mathrm{N}$ & $\mathrm{S}$ & $\mathrm{O}^{[\mathrm{d}]}$ & \\
\hline 49.8 & 7.8 & 4.0 & 0.5 & 33.6 & \\
\hline \multicolumn{6}{|c|}{ Atomic ratios } \\
\hline $\mathrm{O} / \mathrm{C}$ & $\mathrm{H} / \mathrm{C}$ & $\mathrm{N} / \mathrm{C}$ & $\mathrm{S} / \mathrm{C}$ & & \\
\hline \multicolumn{6}{|l|}{$[-]$} \\
\hline 0.50 & 1.88 & 0.069 & 0.003 & & \\
\hline \multicolumn{6}{|c|}{ Physical characteristics } \\
\hline $\begin{array}{l}\text { Ash } \\
\text { [wt.\%] }\end{array}$ & $\mathrm{VM}^{[\mathrm{g}]}$ & $\mathrm{C}_{\mathrm{fix}}{ }^{[\mathrm{h}]}$ & & & \\
\hline 4.2 & 79.2 & 16.6 & & & \\
\hline \multicolumn{6}{|c|}{ Energy characteristics } \\
\hline HHV & Fuel Ratio & & & & \\
\hline$\left[\mathrm{J} \mathrm{g}^{-1}\right]$ & - & & & & \\
\hline 22.47 & 0.21 & & & & \\
\hline
\end{tabular}

[a] Neutral Detergent Fibre. [b] Acid-Detergent Fibre. [c] Acid Detergent Lignin. [d] calculated by difference. [e] calculated by multiplying the total nitrogen value by a factor of 6.25 . [f] organic $\mathrm{C}=$ total $\mathrm{C}$ corrected by the Carbonate content. [g] Volatile Matter. [h] Fixed Carbon. Hemicellulose = NDF - ADF. Cellulose $=\mathrm{ADF}-\mathrm{ADL}$ 
Table 2 Percentage of protein-bound free amino acids related to total $\mathrm{N}$ of Brewer's Spent Grains on a dry basis

\begin{tabular}{lll}
\hline Free amino acids & {$\left[\mathrm{wt} . \% \mathrm{db}^{[\mathrm{a}]}\right]$} & {$[\%$ of total N] } \\
\hline Total N & 3.99 & 100 \\
Aspartic acid & 0.50 & 1.32 \\
Threonine & 0.27 & 0.78 \\
Serine & 0.31 & 1.03 \\
Glutamic acid & 0.93 & 2.21 \\
Glycine & 0.30 & 1.40 \\
Alanine & 0.35 & 1.39 \\
Cysteine & 0.14 & 0.39 \\
Valine & 0.71 & 2.14 \\
Methionine & 0.14 & 0.32 \\
Isoleucine & 0.32 & 0.87 \\
Leucine & 0.56 & 1.51 \\
Tyrosine & 0.20 & 0.39 \\
Phenylalanine & 0.38 & 0.81 \\
Histidine & 0.16 & 1.09 \\
Lysine & 0.32 & 1.55 \\
Arginine & 0.37 & 3.00 \\
Proline & 0.63 & 1.91 \\
N analytically identified & & $\mathbf{2 2 . 1 2}$ \\
\hline
\end{tabular}

[a] weight percent on dry basis

Table 2 shows the percentage of protein-bound amino acids (except of tryptophan), with around $22 \%$ in total relative to the total $\mathrm{N}$ content and detected in the dried BSG. As reported by [39] glutamic acid, valine, arginine and proline were detected in major amounts ( $\geq 2 \mathrm{~N} \%)$, aspartic acid, threonine, serine, glycine, alanine, isoleucine, leucine, phenylalanine, histidine, cysteine, methionine and tyrosine in medium amounts (1-2 N\%) as well as cysteine, methionine and tyrosinein in minor amounts $(\leq 1 \mathrm{~N} \%)$. This profile depends on the assimilation of yeast during the brewing process. Yeast remains in BSG after solid-liquid-separation. Additionally, peptides are uptaken and can be particularly related to the remaining nitrogenous components of BSG [38]. During the malting for beer production, protein and carbohydrates may react to form other nitrogen containing compounds via the Maillard reactions [40, 41].

\section{Experimental Procedure}

The experimental procedure and experimental setup of the HTC was decribed in a previous study of the research group [23] and the fresh BSG for each experiment was taken from the same trial batch (Privatbrauerei Hoepfner $\mathrm{GmbH}$, Karlsruhe, Germany). Three operating temperatures $\left(T_{R}=200,220,240^{\circ} \mathrm{C}\right)$ and one reaction time $\left(t_{R}=2 \mathrm{~h}\right)$ were considered during the two process water $(\mathrm{PW})$ recirculations.

\section{Analytical Methods}

\section{Physicochemical Analysis}

Solid The particle size distribution of BSG was determined in a sieving machine type VS 1000 (Retsch GmbH, Haan, Germany) according to DIN 66165 after freeze drying (Martin Christ Gefriertrocknungsanlagen $\mathrm{GmbH}$, Osterode, Germany). After grinding the BSG and its HCs to powder in a CryoMill (Retsch GmbH, Haan, Germany), their ultimate composition was determined with an Euro EA-CHNSO Elemental Analyzer (HEKAtech GmbH, Wegberg, Germany). The oxygen content was calculated by Eq. 1. The moisture content, volatile matter (VM) and ash content were determined by DIN EN 12880:2000, and DIN EN 15,148:2009, respectively. To eliminate the carbonates, the determination of ash was performed at $1000{ }^{\circ} \mathrm{C}$ for $60 \mathrm{~min}$ (oven temperature of Elemental Analyzer). The fixed carbon $\left(\mathrm{C}_{\mathrm{fix}}\right)$ was calculated by Eq. 2. The total structural composition of the biomass was determined with the Van Soest analysis (ADF, $\mathrm{NDF}, \mathrm{ADL}$ ) and the total amount of lipids was determined by their extraction according to VO (EG) 152/2009 III H 2009-01 and 152/2009 III C 2009-01 [42]. For the calculation of the protein content, the nitrogen content was determined according to the Kjeldahl method and multiplied by the factor 6.25, given for cereal products [43]. The mineral composition of BSG and its HCs was analyzed by means of inductively coupled plasma optical emission spectrometry in an ICP-OES Spectrometer (Agilent Technologies, Santa Clara, USA) after microwave digestion (Anton Paar Germany $\mathrm{GmbH}$, Ostfildern, Germany). Results are presented in Tab S1 in the Supplementary Materials but not discussed.

Liquid The liquid phase was filtered $(0.45-\mu \mathrm{m}$ polypropylene filters) and adequately diluted with the eluent for sample preparation prior to high performance liquid chromatography (HPLC) or liquid-liquid-extraction prior to gas chromatography with mass spectroscopy (GC-MS). Subsequently, HPLC was used to determine and quantify the carbohydrate-, phenol- and protein-related reaction products and GC was applied for detection of lipidrelated reaction products, in the liquid phase after each HTC. Equipment and procedures used for the detection of saccharides, organic acids, aldehydes, and alcohols were described in detail in a recently published study [6].

To validate the results for 5-hydroxymethylfurfural (HMF), methylfurfural, and furfural, another HPLC system (Merck Hitachi, Düsseldorf, Germany) equipped with the column Lichrosper 100 RP-18 was used, which was driven with an eluent composition of water and acetonitrile (90/10) and a flow rate of $1.4 \mathrm{~mL} \mathrm{~min}^{-1}$ at $20^{\circ} \mathrm{C}$.

The amino acids were analyzed according to $\mathrm{VO}$ (EG) 152/2009 by using a Biochrom 30 (Biochrom LTD, 
Cambridge, UK) equipped with a PEEK pre-column $(100 \times 4.6 \mathrm{~mm})$ and main column $(200 \times 4.6 \mathrm{~mm})$ [44]. After gradient separation, the concentrations of amino acids were determined at 2 wave lenghts of 570 and $440 \mathrm{~nm}$ after postcolumn derivatization at $135{ }^{\circ} \mathrm{C}$ by means of ninhydrin. Tryptophan, which has to be detected by separeted method, was neglected.

The phenols such as resorcinol, catechol, phenol, vanillin, 2.6-methoxyphenol, 4-Methylguaiacol as well as m-, o-, p-cresol were measured by a Merck Hitachi Primade HPLC system equipped with the column Kinetex 2.6 u PFP 100A (Phenomenex LTD, Aschaffenburg, Germany) and a DiodeArray-Detector. The eluent consisted of $7.6 \mathrm{~mL} \mathrm{H}_{3} \mathrm{PO}_{4}$, $12.9 \mathrm{~g} \mathrm{NaH}_{2} \mathrm{PO}_{4}$ dissolved in $2 \mathrm{~L} \mathrm{H}_{2} \mathrm{O} / \mathrm{MeOH}$ (80/ 20), which was used at a flow rate of $1.0 \mathrm{~mL} \mathrm{~min}$.

For identification of the fatty acid pattern the pretreated liquid samples were extracted 3 times with petroleum ether $\left(30-50^{\circ} \mathrm{C}\right)$. In the following step, petroleum ether was carefully evaporated. Then, $0.2-0.3 \mathrm{~g}$ of the sample extract was dissolved in $5 \mathrm{~mL}$ of di-isopropyl ether. Subsequent methylation was done by adding $0.2 \mathrm{M}$ methanolic solution of trimethylsulfoniumhydroxide (TMSH) to an aliquot of the sample extract, dissolved in di-isopropyl ether in a ratio of 1:2 (v/v). For analysis, this mixture was injected into a GC with Flame Ionisation Detection (GC-FID) of type 7890A (Agilent Technologies GmbH, Waldbronn, Germany).

The total dissolved organic carbon content (DOC) of the filtrate was determined by liquid chromatography-organic carbon detection LC-OCD (DIMATEC Analysentechnik $\mathrm{GmbH}$, Essen, Germany). The concentrations of ammonium in liquids were measured by means of the barcode cuvette tests LCK 303 in the spectral photometer DR6000 (HACH LANGE GmbH, Düsseldorf, Germany). The DOC values were used to create a mass-related carbon distribution (see Eq. 12 and Fig. 10).

To validate the presence of some carboxylic acids and phenols as well as other intermediate products, a GC-MS analysis was performed by a GC system of type 7890A equipped with a MS of type Agilent 5975C (Agilent Technologies, Santa Clara, USA). Here only a qualitative analysis was performed.

\section{Structural Analysis}

Two different methods were used for gaining insights about the carbon and nitrogen related structure of the $\mathrm{HC}$ and its surface functionalities. Whereas, Fourier Transmission Infrared Spectroscopy (FT-IR) presents the more sensitive and selective technique and also provides the possibility to gain insights about the expired (de-)polymerization of the biochemical structure of BSG (bulk), X-ray photoelectron spectroscopy (XPS) only enables a study of the evolution of functional groups on the HC's surface mostly resulting from secondary char formation [45]:

1. FT-IR spectra of the intial feedstock and produced HCs were acquired, using Bruker ALPHA II coupled with a diamond Attenuated Total Reflector (ATR) (PLATINUM-ATR, Germany). The pellet technique was used mixing $2 \mathrm{mg}$ of dried BSG or its HCs with $200 \mathrm{mg}$ of pre-dried and pulverized spectroscopic-grade potassium bromide (Merck and Co., Whitehouse Station, NJ) and pressing at compressive pressure of $1 \mathrm{GPa}$. The spectra were registered in the range from 400 to $4000 \mathrm{~cm}^{-1}$ by averaging 24 scans.

2. XPS spectra were recorded using a Kratos Axis ULTRA equipment, which provided the extent of the surface analyzed by XPS normally probes to a depth of $5 \mathrm{~nm}$ and the lateral size is determined by the X-ray spot used. The spectrometer is equipped with a $\mathrm{Al} \mathrm{K} \alpha$ monochromated source $(\mathrm{ho}=1486.7 \mathrm{eV})$. X-ray gun power was set to $120 \mathrm{~W}$ ( $8 \mathrm{~mA}$ emission current). Binding energy calibration was made using C $1 \mathrm{~s}(284.8 \mathrm{eV})$. The survey scans were acquired using $30 \mathrm{eV}$ pass energy, $1 \mathrm{eV}$ step size and $100 \mathrm{~ms}$ dwell times. All high resolution spectra were acquired using $10 \mathrm{eV}$ pass energy, $0.1 \mathrm{eV}$ step size and $260 \mathrm{~ms}$ dwell times. Casa XPS was used for data interpretation. Shirley background subtractions were employed in all data. The $\mathrm{C} 1 \mathrm{~s}, \mathrm{O} 1 \mathrm{~s}$ and $\mathrm{N} 1 \mathrm{~s}$ peaks were fitted using GL(30) line shapes: a combination of a Gaussian $(70 \%)$ and Lorentzian (30\%). The atomic percentages were calculated from the peak areas in the acquired high resolution spectra. Casa XPS sensitivity factors were used for atomic percentage quantification analysis (where RSF of $\mathrm{C} 1 \mathrm{~s}=0.278, \mathrm{O} 1 \mathrm{~s}=0.780$ and $\mathrm{N} 1 \mathrm{~s}=0.477)$. The $\mathrm{C}$ $1 \mathrm{~s}$ peak was deconvoluted in $\mathrm{C}-\mathrm{C}(\sim 284.8 \mathrm{eV}), \mathrm{C}-\mathrm{N}$ $(\sim 285.6 \mathrm{eV}), \mathrm{C}-\mathrm{O}(\sim 286 \mathrm{eV}), \mathrm{C}=\mathrm{O}(\sim 288 \mathrm{eV})$ and $\pi-\pi^{*}$ sat $(\sim 291 \mathrm{eV})$. The $\mathrm{O} 1 \mathrm{~s}$ peak was deconvoluted in $\mathrm{C}=\mathrm{O}(\sim 531.3 \mathrm{eV})$ and $\mathrm{C}-\mathrm{O}(\sim 532.8 \mathrm{eV})$. The $\mathrm{N} 1 \mathrm{~s} \mathrm{peak}$ was deconvoluted in pyridinic $(\sim 399.4 \mathrm{eV})$, amine $(\sim$ $399.9 \mathrm{eV})$, pyrrolic $(\sim 400.5 \mathrm{eV})$, quaternary $(\sim 401.5 \mathrm{eV})$ and inorganic or chemisorbed $(\sim 402.4 \mathrm{eV})$.

\section{Scanning electron microscopy.}

Scanning electron microscopy (SEM) of dried and pulverized HCs was performed with a GeminiSEM 500 from Zeiss (software: SmartSEM Version 6.01) with a thermal Schottky field emitter cathode. The variable pressure system allowed pressures up to $500 \mathrm{~Pa}$ that were applied in the case of nonconductive samples. For secondary electron (SE) images, the SEM was equipped with an inlens SE detector, an Everhart-Thornley detector, and a variable pressure secondary electrons (VPSE) detector. 


\section{Uncertainty analysis.}

All experiments were conducted twice as it was known from prior experiments that the overall error is around $\pm 5 \%$ (relative) and the reproducibility is even better. Due to a good laboratory praxis the analytical methods are regularly controlled by including the calibration standards within each detection sequence. This procedure guaranteed an analytical or a systematic error below $\pm 5 \%$.

\section{Calculations}

The oxygen content presented in Table 1 was calculated by difference related to $100 \%$ dry matter (DM) of BSG as well as its HCs:

$O(w t \%)=100 \%-C(w t \%)-H(w t \%)-N(w t \%)-S(w t \%)-A s h(w t \%)$

The fixed Carbon $\left(\mathrm{C}_{\mathrm{fix}}\right)$ content presented in Table 1 was calculated by difference related to $100 \%$ DM of BSG as well as its HCs:

$C f i x(w t \%)=100 \%-V M(w t \%)-A s h(w t \%)$ where $E D R_{H C}$ is the Energy Densification Ratio of $\mathrm{HCs}$ which is based on the calculated higher heating value of the $\mathrm{HC}\left(H H V_{H C_{d b}}\right)$ divided by the higher heating value of the feedstock Brewer's spent grains (BSG) $\left(H H V_{B S G_{d b}}\right)$ in $\mathrm{J} \mathrm{g}^{-1}$. The Energy Yield $\left(E Y_{H C}\right)$ considers the HC yield $\left(Y_{H C}\right)$, which is calculated by the mass of $\mathrm{HC}\left(m_{H C}\right)$ and the mass of BSG $\left(m_{B S G}\right)$ considered on a dry basis.

The higher heating values for the BSG and its $\mathrm{HCs}$ were calculated using the following equation [46]:

$$
\begin{aligned}
H H V= & 0.3491 \times C+1.1783 \times H+0.1005 \times S-0.1034 \\
& \times 0-0.0151 \times N-0.0211 \times \text { ash }
\end{aligned}
$$

Where the elements have to be inserted as measured in weight percent (wt.\%).

The fuel ratio (FR) evaluates the combustibility of the BSG and the produced HCs and considers the fixed carbon content $\left(\mathrm{C}_{\mathrm{fix}}\right)$ as well as the content of volatile matter $(\mathrm{VM})$.

Fuelratio $=\frac{\mathrm{C}_{\mathrm{fix}}}{\mathrm{VM}}$

The organic carbon retention efficiencies related to Brewer's Spent Grains (BSG) and to process water of the last recirculation step were calculated as:

$C_{e f f}=\frac{\left(\left(C_{H C}-A s h_{575^{\circ} \mathrm{C}}-A s h_{1000^{\circ} \mathrm{C}}\right) \times \frac{M_{C}}{M_{C O_{3}^{2-}}}-\right) \times m_{H C}}{\left(\left(C_{B S G}-\left(\left(A s h_{575^{\circ} \mathrm{C}}-A s h_{1000^{\circ} \mathrm{C}}\right) \times \frac{M_{C}}{M_{C 0_{3}^{2-}}}-\right) \times m_{B S G}+C_{P W_{\text {initial } / \text { st }}} \times m_{P W}\right.\right.} \times 100 \%$

For calculation of the values for hemicellulose, cellulose and lignin the following equations were applied:

Hemicellulose $=N D F-A D F$

Cellulose $=A D F-A D L$

Whereas NDF designates the neutral detergent fiber, ADF is the acid detergent fiber and ADL is the acid detergent lignin.

Energy characteristics of BSG and its HCs were evaluated by using two parameters, namely the energy densification ratio $\left(\mathrm{EDR}_{\mathrm{HC}}\right)$ and the energy yield $\left(\mathrm{EY}_{\mathrm{HC}}\right)$. They were calculated according to the following equations:

$Y_{H C}=\frac{\mathrm{m}_{\mathrm{HC}}}{\mathrm{m}_{\mathrm{BSG}}}$

$E D R_{H C}(\%)=\frac{\mathrm{HHV}_{\mathrm{HC}_{\mathrm{db}}}}{\mathrm{HHV}_{\mathrm{BSG}_{\mathrm{db}}}} \times 100 \%$

$\mathrm{EYHC}(\%)=\mathrm{YHC} \times \mathrm{EDRHC}$
$\mathrm{C}_{\text {eff }}$ is the organic carbon retention efficiency related to the BSG weighed in, $\mathrm{C}_{\mathrm{HC}}$ the total carbon content of the hydrochar, $\mathrm{m}_{\mathrm{HC}}$ is the mass of the hydrochar, $\mathrm{C}_{\mathrm{BSG}}$ is the total carbon content of the $\mathrm{BSG}$ and $\mathrm{m}_{\mathrm{BSG}}$ is the initial mass of BSG (all on a dry basis). $\mathrm{C}_{\mathrm{PW} \text { _initial/1st }}$ is the concentration of dissolved organic carbon, which has to be mutliplied by the mass of the recirculated $\mathrm{PW}\left(\mathrm{m}_{\mathrm{PW}}\right)$ for calculation of the weight of total organic carbon in the PW.

$\mathrm{C}_{\text {eff-rPW }}=\left(\frac{\mathrm{C}_{\mathrm{eff}_{1 \mathrm{st} / 2^{\mathrm{nd}}}}}{\mathrm{C}_{\mathrm{eff}_{\text {initial/1/15 }}}}\right) \times 100 \%$

$\mathrm{C}_{\text {eff-rPW }}$ describes the carbon retention efficiency regarding the additional $\mathrm{HC}$ formed from the carbon compounds dissolved in the recirculated PW.

To illustrate how well the carbon balance in the PW after the two recirculation steps could be closed, the following equation was used:

$\mathrm{C} \%=\frac{\frac{\mathrm{M}_{\text {Carbon }}}{\mathrm{M}_{\text {Reaction Product }}} \times \mathrm{c}_{\text {Reaction Product }}}{\mathrm{c}_{\mathrm{DOC}}} \times 100 \%$ 
The carbon percentage of each reaction product $(\mathrm{C} \%)$ was calculated considering the molar percentage of carbon $\left(\mathrm{M}_{\text {Carbon }}\right)$ in the reaction product $\left(\mathrm{M}_{\text {Reaction Product }}\right)$ depending on its concentration ( $c_{\text {Reaction product }}$ ) related to the concentration of dissolved organic carbon $\left(\mathrm{c}_{\mathrm{DOC}}\right)$.

The nitrogen retention efficiencies related to Brewer's Spent Grains (BSG) and the load of the recirculated process water were calculated as:

$N_{\text {eff }}=\frac{N_{H C} \times m_{H C}}{N_{B S G} \times m_{B S G}+N_{P W_{\text {initial } / \text { st }}} \times m_{P W}} \times 100 \%$

$\mathrm{N}_{\text {eff }}$ is the nitrogen-retention efficiency related to the BSG weighed in, $\mathrm{N}_{\mathrm{HC}}$ the nitrogen content of the $\mathrm{HC}, \mathrm{m}_{\mathrm{HC}}$ is the mass of the hydrochar, $\mathrm{N}_{\mathrm{BSG}}$ is the total nitrogen content of the BSG and $\mathrm{m}_{\mathrm{BSG}}$ is the initial mass of BSG (all on a dry basis). $\mathrm{N}_{\mathrm{PW} \_ \text {initial//1st }}$ is the weight of nitrogen, which was calculated on the basis of the total nitrogen bound in the recirculated $\mathrm{PW}$ and its mass $\mathrm{m}_{\mathrm{PW}}$.

$\mathrm{N}_{\mathrm{eff}-\mathrm{PPW}}=\left(\frac{\mathrm{N}_{\mathrm{eff}_{1 \mathrm{~s} /} / 2^{\mathrm{nd}}}}{\mathrm{N}_{\mathrm{eff}_{\text {initia//1st }}}}\right) \times 100 \%$

$\mathrm{N}_{\text {eff-rPW }}$ describes the nitrogen-retention efficiency regarding the additional $\mathrm{HC}$ formed from the nitrogen compounds dissolved in the recirculated PW.

\section{Results and Discussion}

The challenge is that information about the reactions occuring is included in a lot of different measurements with diverse methods. Therefore, firstly the impact of the reaction parameters is reported and then, the findings are collected giving an insight on the behaviour of different compounds in biomass.

In order to understand the chemistry of HTC, Fig. 1 shows the most important reactions occuring at hydrothermal conditions. There is the hydrolysis of polar bonds like ethers or amines (see A in Fig. 1). This is important for biomass conversion, because large polysaccharides like cellulose or hemicellulose are splitted into monosaccharides, mainly glucose, accomplished by water elimination (see B in Fig. 1). Also esters and amides are hydrolysed, which means that proteins and lipids are hydrolysed to smaller molecules. In addition, decarboxylation of acids in general occurs (not shown). The saccharide rings of glucose and fructose can be splitted by reverse aldol condensation. On the other hand, the formation of HC from HMF might be an aldol condensation (see C in Fig. 1). D (see Fig. 1) is an example for Keto-Enol-Tautomerisation, which here is the formation of fructose to glucose and vice versa. The Strecker degradation (see E in Fig. 1) is a reaction in which consecutive reactions

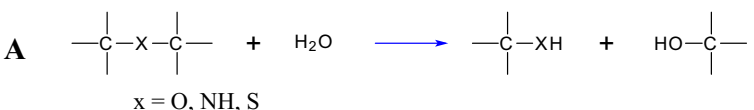

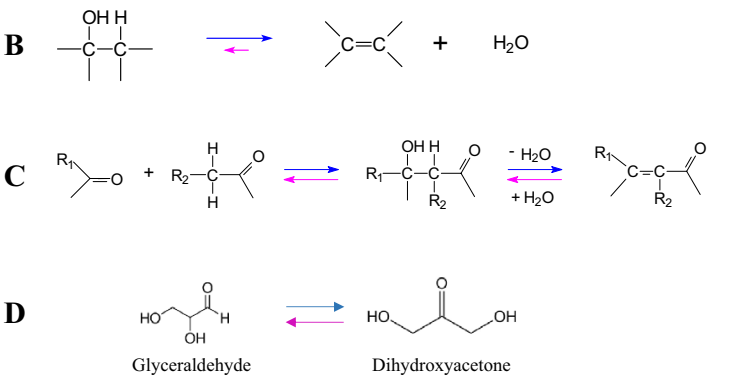

$\mathbf{E}$

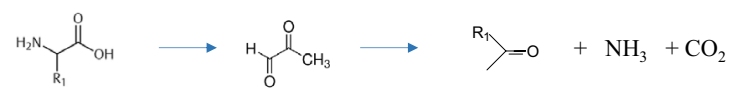

Fig. 1 The most important reaction steps occuring during hydrothermal conversion of bio-based compounds. A Hydroylsis of ethers, amines etc., B Water elimination, $\mathbf{C}$ Aldol addition and aldol condensation and their reverse reactions, D Keto-Entol Tautomerisation (example), E Strecker degradation

of saccharides, here to pyruvaldehyde, lead to the degradation of amino acids, thus forming a product of the hydrolysis of proteins. All these reactions are promoted by the special properties of water [47]. The presence of proteins, and consecutively amino acids, together with saccharides enable the formation of nitrogen heterocyclic compounds via the Maillard reaction (see Fig. 2) [29]. BSG already contains Maillard products because of the malting step during brewing. Thus, these heterocyclic nitrogen containing compounds may become a part of the $\mathrm{HC}$ structure [30].

\section{Effect of Temperature and Recirculation Steps on Hydrochar Mass Yields, Physicochemical and Energetic Characteristics}

In Table 3 it is shown that the applied HTC conditions result in significant changes of the physicochemical as well as energy characteristics of the BSG described in Table 1. The results of varying the reaction temperature $\left(T_{R}\right)$ as well as the PW recirculation (see Table 1) show that $T_{R}$ had a higher impact on HCs than the reuse of PW. In general, the increase of $T_{R}$ results into the decrement of the VM, which also corresponds to an increase of the FR. Conversely, $\mathrm{C}_{\text {fix }}$ values of HCs produced at 200, 220 and $240{ }^{\circ} \mathrm{C}$ showed an increase of more than 50, 70 and up to $100 \%$ relative to BSG (see Table 1). However, the HCs produced with the $1^{\text {st }}$ recirculated PW showed the highest increase with 62,78 and up to $100 \%$.

Correlating with the carbon content as well as under consideration of the contents of other elements $(\mathrm{N}, \mathrm{H}, \mathrm{S}$, 
<smiles>CCC(C)C(O)C(O)C(O)C(O)C(O)C(O)C(O)C(O)C(O)C(O)C(O)C(O)C(O)CO</smiles>

Glucose

Lysine

Glycosylamines

Shiff base

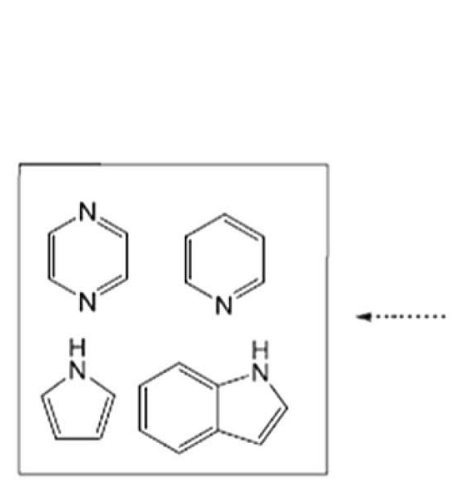

$\mathrm{N}$-containing compounds

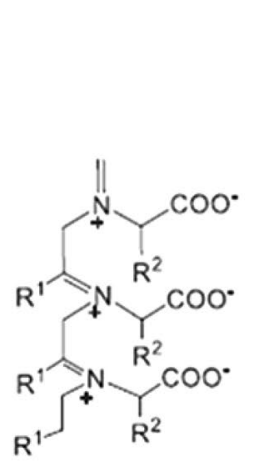

Melanoidins

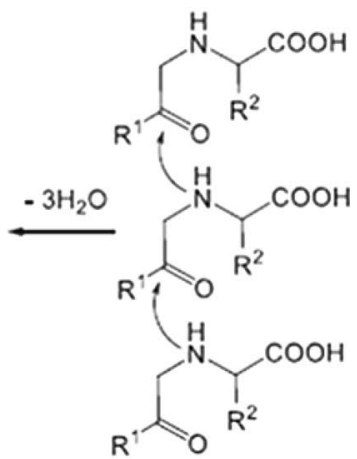

$+3$

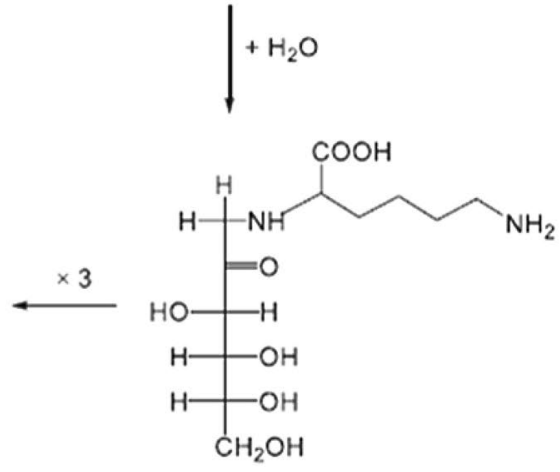

Amadori compound<smiles>[R]=C</smiles><smiles>[Z1]CCCCN</smiles>

Fig. 2 Proposed mechanisms of Maillard reaction pathways during HTC, reprinted with kind permission from [29]

O), listed under "Chemical Characteristics of BSG" (see Table 1) and its HCs (see Table 3), the HHV can be calculated (see Eq. 8) [46]. Whereas, the HHV had already been increased after the initial HTC-run at $200^{\circ} \mathrm{C}$, a recirculation reduced it. This could also be observed for the $2^{\text {nd }}$ recirculation after the HTC-run at $220{ }^{\circ} \mathrm{C}$. However, relative to the HHV of BSG (see Table 1), those of HCs produced at 200, 220 and $240{ }^{\circ} \mathrm{C}$ in water, after the $1^{\text {st }}$ and $2^{\text {nd }} \mathrm{PW}$ recirculation were more than 20,30 and or even up to $40 \%$ higher. These increases can be expressed by the energy densification ratio $\left(\mathrm{EDR}_{\mathrm{HC}}\right)$. In total, these $\mathrm{HCs}$, even without $\mathrm{PW}$ recirculation, might compete with standardized solid fuels such as German Lignite [46].

In addition, the evaluation of the $\mathrm{O} / \mathrm{C}$ and $\mathrm{H} / \mathrm{C}$ atomic ratios, shown in the van Krevelen plot (see Fig. 3), allowed the general conclusion that $T_{R}$ is the reaction parameter exhibiting of the highest impact. With increasing $T_{R}$ the oxygen and hydrogen content, relative to the carbon, is reduced, indicating on the one side the depolymerization of the cellulosic fraction of BSG and the following deoxygenation as well as on the other side the dehydration from hydrolysed (oligo-)saccharides [34]. Thus, the reuse of the PW has a minor effect at $\mathrm{T}_{\mathrm{R}}$ below $220{ }^{\circ} \mathrm{C}$, except for the initial $\mathrm{pH}$ of the next HTC-run and initialising the aforementioned reactions [48]. However, applying $240{ }^{\circ} \mathrm{C}$ resulted in an increment of $\mathrm{H} / \mathrm{C}$ ratios, which points out a higher degree of carbonization or aromaticity [35].

Since BSG contains amino, carboxylic, and thiol groups [49], it also includes heteroatoms, the ratios of N/C as well as N/S were calculated and given in Table 3 . The results showed that at $200{ }^{\circ} \mathrm{C}$, the N/C decreased by 0.16 and S/C increased by 0.001 relative to BSG. The ratios slightly increased with $T_{R}$.

At $220{ }^{\circ} \mathrm{C}$, a $2^{\text {nd }}$ recirculation even resulted in an $\mathrm{EY}_{\mathrm{HC}}$ (see Eq. 7) of more than $90 \%$ due to a $\mathrm{Y}_{\mathrm{HC}}$ (see Eq. 5) of more than $70 \%$. Moreover, small differences in the $\mathrm{VM}, \mathrm{C}_{\text {fix }}$ and an increase in the ash content after the $1^{\text {st }}$ recirculation proved that a $2^{\text {nd }}$ recirculation is necessary for an efficient 


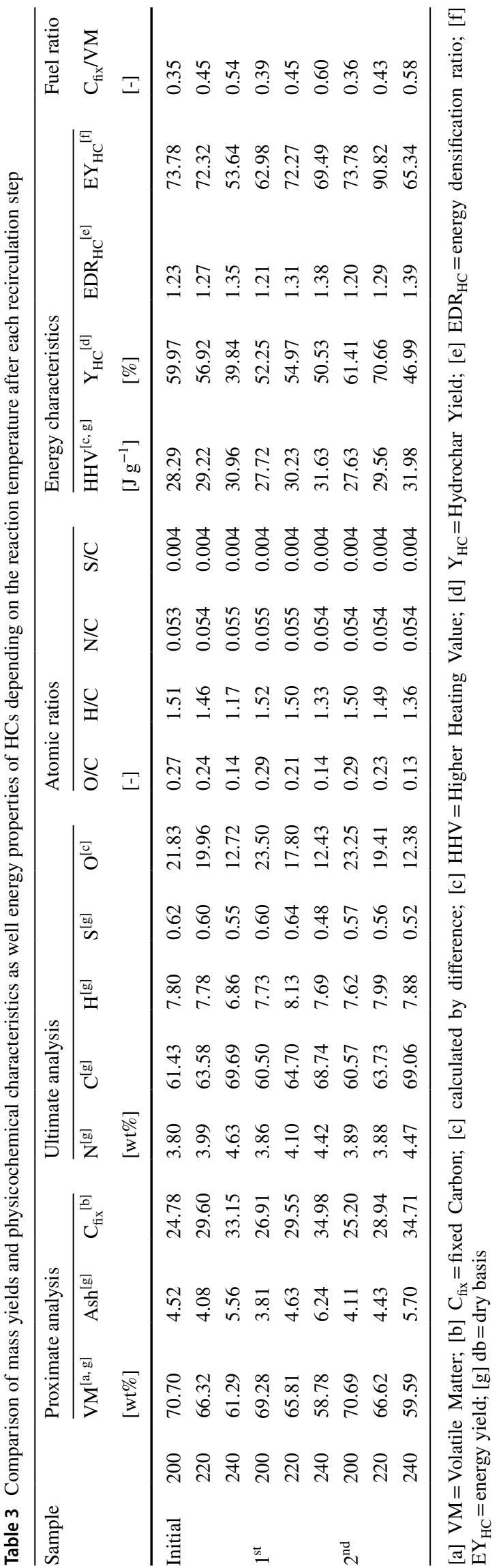

conversion. The increase in ash of HCs related to the BSG is mostly caused by a concentration of elements such as phosphorus, sulphur as well as of earth alkali metals such as calcium and magnesium but also iron and zinc to a low extent [50]. Other elements could not be detected, partly due to the fact they are below the detection limit (see Table S1 in Supplemmentary Materials).

The FR (see Eq. 9) of HCs, which leads to an evaluation of their combustibility, reached its maximum at $240{ }^{\circ} \mathrm{C}$, after the initial HTC-run, $1^{\text {st }}$ and $2^{\text {nd }}$ recirculation. At $240{ }^{\circ} \mathrm{C}$, it was more than 2.8 times higher than the FR of the feedstock (see Table 3). Nevertheless, it might be associated to the energy input and larger loss of carbon to the PW and PG, in comparison to the experiments at $220^{\circ} \mathrm{C}$ (see Fig. 4). However, efficiencies regarding recirculation of carbon $\left(\mathrm{C}_{\text {eff-rPW }}\right)$ and nitrogen $\left(\mathrm{N}_{\text {eff-rPW }}\right)$ during $\mathrm{HTC}$ at $200{ }^{\circ} \mathrm{C}$ are better than at the other $\mathrm{T}_{\mathrm{R}}$ (see Table $\mathrm{S} 2$ ).

It has to be considered that all data in Table 3 and Fig. 4 are given relative to the carbon input by BSG. By PW recirculation the total carbon input increased. As the organic compounds in PW are those which have not reacted to HC, it would be misleading to consider them for calculating the $\mathrm{Y}_{\mathrm{HC}}$. Compounds like acetic acid will not contribute directly to $\mathrm{HC}$ formation, how often ever they are recirculated, but influencing feedwater $\mathrm{pH}$. Noting that, it is one of the most important results that carbon in PW not drastically increased by recirculation (see Fig. 4).

\section{Effect of Temperature and Recirculation Steps on the Structure of Hydrochar}

\section{FT-IR study of Brewer's Spent Grains and its Hydrochars}

The FT-IR spectra of the HCs produced after using water and recirculated PW are shown in Fig. 5. They were used to evaluate the effect of PW recirculation on the decomposition pathways of BSG. For this purpose, the impact on the condensation, amide formation and polymerization reactions to form HCs and as consequence, on their physicochemical characteristics will be properly addressed [6,51].

The FT-IR bands between 3700 and $3000 \mathrm{~cm}^{-1}$ (see Fig. 5) are ascribed to stretching vibration of aliphatic $-\mathrm{OH}$ (hydroxyl and carboxyl) as well as stretching vibration of the free- $\mathrm{COOH}$, indicating the presence of polysaccharides and proteins. The decrease of wavenumbers shows the dehydration promoted by enhancing the $T_{R}$. This is especially promoted, if the feedwater $\mathrm{pH}(\mathrm{pH}=3.5-4.0)$ is lowered from the beginning by using recirculated PW. This is different from the insights of $\mathrm{Xu}$ et al., who applied a comparable process, but they included mixing of sewage sudge and a $\mathrm{PW}$ with a pH higher than 6.5 [26].

The bands around the peak $2922 \mathrm{~cm}^{-1}$ correspond to methylene $\left(-\mathrm{CH}_{2}\right)$ stretching vibrations. Here, further 
Fig. 3 Coalification degree of hydrochars obtained from hydrothermal carbonization of Brewer's Spent Grains with water and after recirculation of its process water in two further steps at $200,220,240{ }^{\circ} \mathrm{C}$ for $2 \mathrm{~h}$ (e.g. $2^{\text {nd }} 220$ ) illustrated in the van Krevelen diagram by plotting $\mathrm{H} / \mathrm{C}$ atomic ratios versus $\mathrm{O} / \mathrm{C}$ atomic ratios. Whereas the rhombus-shaped data points stand for the initial HTC-run, the triangle-shaped and the square-shaped data points stand for the HTC-run after the $1^{\text {st }}$ and the $2^{\text {nd }}$ recirculation. $\mathrm{BSG}=$ Brewer's Spent Grains
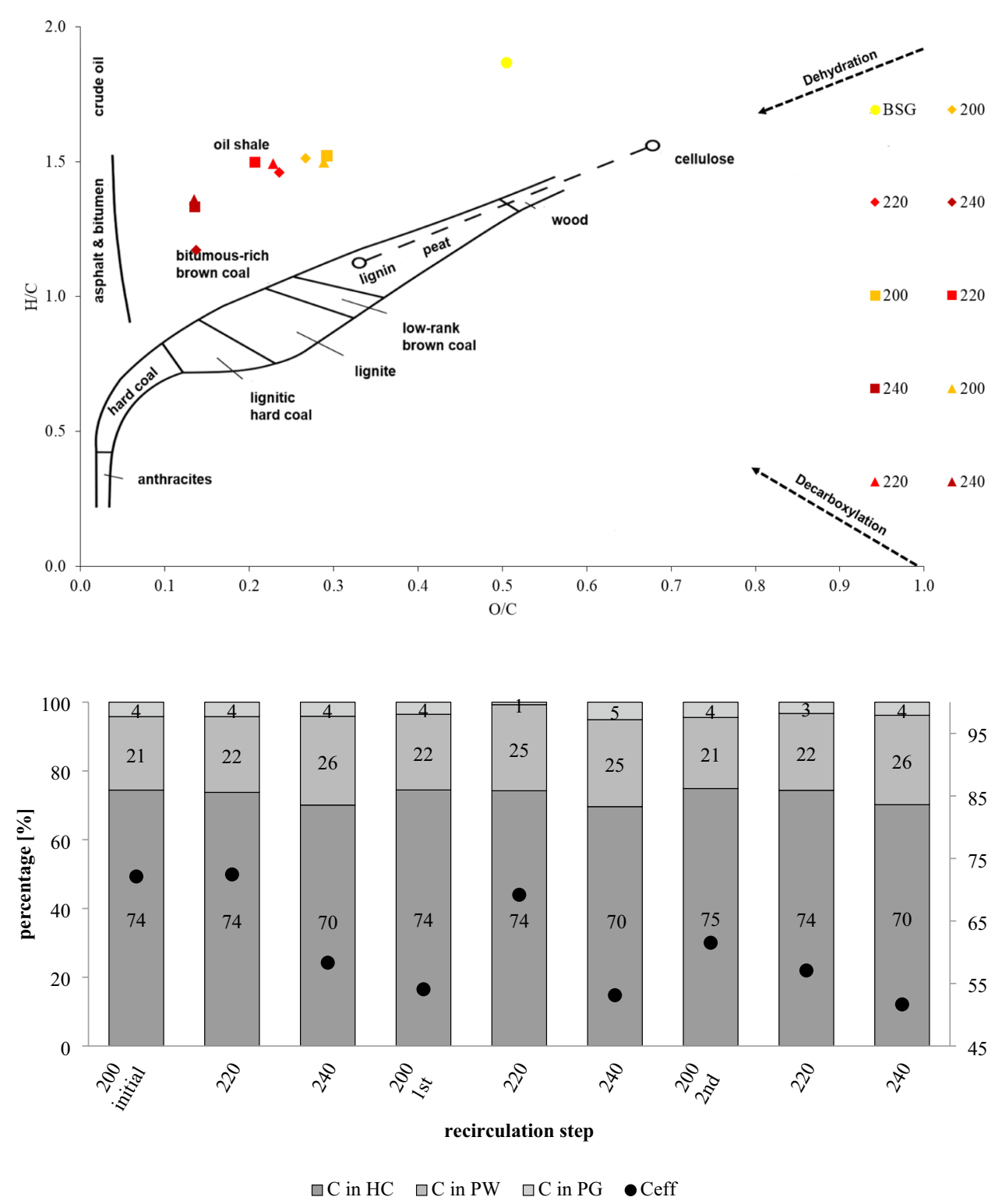

$\square \mathrm{C}$ in $\mathrm{HC} \quad \square \mathrm{C}$ in $\mathrm{PW} \quad \square \mathrm{C}$ in PG $\bullet$ Ceff
Fig. 4 Carbon distribution (primary or left y-axis) and efficiencies (secondary or right $\mathrm{y}$-axis) related to the product phases after Hydrothermal Carbonization of Brewer's Spent Grains with water and two further recirculation steps of its process water. The process gas is assumed as $100 \% \mathrm{CO}_{2}$. $\mathrm{HC}=$ hydrochar, $\mathrm{PW}=$ process water, $\mathrm{PG}=$ process gas, $C_{f i x}=$ fixed carbon broadening as well as a decreasing intensity show an ongoing dehydration by enhancing the $T_{R}$ with every recirculation [52]. HCs produced at 200 and $220^{\circ} \mathrm{C}$ are characterized by a loss of aliphatic $-\mathrm{CH},-\mathrm{CH}_{2}$ and $-\mathrm{CH}_{3}$ groups (3000-2800 $\mathrm{cm}^{-1}$ ), while the importance of aromatic C-H and C-C groups increases (1800-750 $\mathrm{cm}^{-1}$ ), as can be seen in Fig. 5 [53]. Furthermore, the intense absorption peaks around $1000 \mathrm{~cm}^{-1}$, representing the $\mathrm{C}-\mathrm{O}$ and $\mathrm{C}-\mathrm{O}-\mathrm{C}$ stretching and illustrating a characteristic region of cellulose-typical structures, continuously disappeared [54]. This implies reduction by dehydration and decarboxylation, which is in agreement with the observations in the van Krevelen plot in Fig. 3. The peaks between 1800 and $1650 \mathrm{~cm}^{-1}$, which result from $\mathrm{C}=\mathrm{O}$ vibrations of esters or quinones $(\mathrm{C}-(\mathrm{C}=\mathrm{O})-\mathrm{O}-\mathrm{C})$, carboxylic acids $(\mathrm{C}(=\mathrm{O}) \mathrm{OH})$ or aldehydes $(\mathrm{R}-(\mathrm{C}=\mathrm{O})-\mathrm{H})$ sligthly decreased. Furthermore, the appearance of peaks between 1650 and $1450 \mathrm{~cm}^{-1}$ due to $\mathrm{C}=\mathrm{C}$ vibrations, and a well-defined peak in the region $850-780 \mathrm{~cm}^{-1}$ correspond to the deformation of $\mathrm{C}-\mathrm{H}$ out of plane by enhancing the $\mathrm{T}_{\mathrm{R}}$ (initial 200 and 220 vs. $240{ }^{\circ} \mathrm{C}$ ). Both are comparable to the $\mathrm{HCs}$ produced at 200 and $220^{\circ} \mathrm{C}$ with water and after the $2^{\text {nd }}$ recirculation. For the other $\mathrm{HCs}$ obtained, vibrations are more depressed. Additionally, the peaks located at 1600 and $1520 \mathrm{~cm}^{-1}$ are ascribed to $\mathrm{N}-\mathrm{H}$ (amine- $\mathrm{N})$ and $\mathrm{C}=\mathrm{N}$ (pyridinic- $\mathrm{N}$ ) vibration $[55,56]$, which may be a hint to Maillard products (see Fig. 2).

Concerning proteins, changes in the regions between 1440 and 1400 as well as $1020-1220 \mathrm{~cm}^{-1}$ are visible, which are attributed to amine and amide structures. In addition, the peak at $559 \mathrm{~cm}^{-1}$, which is assigned to the bending vibrations of the $\mathrm{O}=\mathrm{C}-\mathrm{N}$ group $[57,58]$, indicates proteins. It is distinctly realised from the FT-IR spectra that the variety of 


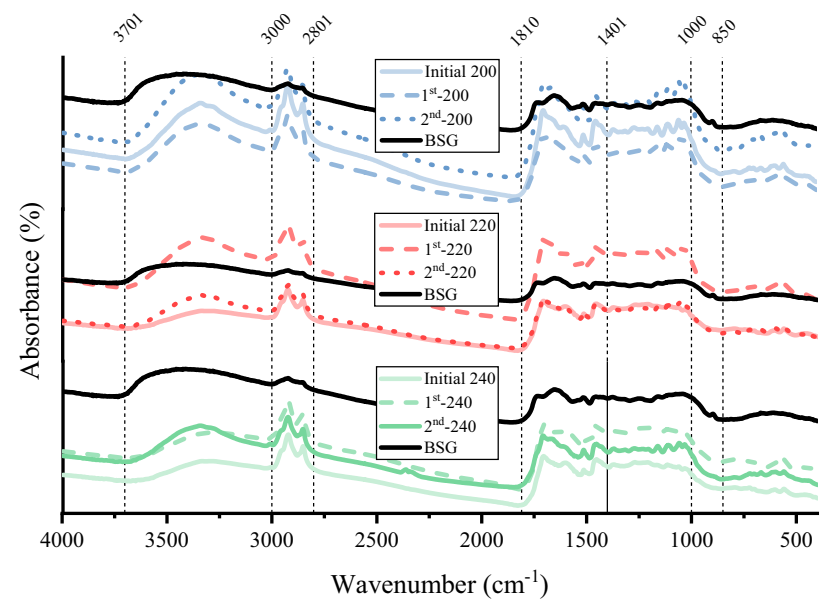

Fig. 5 FT-IR of Brewer's Spent Grains and its hydrochars produced at 200,220 and $240{ }^{\circ} \mathrm{C}$ with water (initial) and after two recirculation steps of process water $\left(1^{\text {st }}, 2^{\text {nd }}\right)$. BSG $=$ Brewer's Spent Grains

bulk and surface functional groups of $\mathrm{HCs}$ raises with this recirculation, especially the $\mathrm{O}-\mathrm{H}, \mathrm{C}-\mathrm{H}, \mathrm{N}-\mathrm{H}, \mathrm{C}-\mathrm{N}, \mathrm{C}=\mathrm{C}$, $\mathrm{C}=\mathrm{O}$, and $\mathrm{C}=\mathrm{N}$ groups, and would be beneficial for electrochemical and adsorption applications [59]. A higher $T_{R}$ leaded to the disappearance of functional groups such as carboxyl, carbonyl and hydroxyl groups and to an increase of the aromaticity, which is confirmed by an increasing $\mathrm{H} / \mathrm{C}$ ratio with the step of recirculation. This can be seen in Fig. 5 as well as Table 3 and Fig. 3 and contributes to the reduction of VM [53].

\section{XPS study of Brewer's Spent Grains and its Hydrochars.}

After the HTC process, the operating temperature (200, 220 and $240{ }^{\circ} \mathrm{C}$ ) and the recirculation of PW affected the chemical structure of the HCs differently. As shown in Fig. 6, the four main $\mathrm{C} 1 \mathrm{~s}$ peaks $(284.8,285.6,286.5$, as well as $288.3 \mathrm{eV}$ ) are associated to $\mathrm{C}-\mathrm{C}$ (graphitic-C), $\mathrm{C}-\mathrm{N}$ (amine$\mathrm{N}), \mathrm{C}-\mathrm{O}$ (ether-C) as well as $\mathrm{C}=\mathrm{O}$ (ester-C) and $\mathrm{O}=\mathrm{C}-\mathrm{O}$ (aromatic-C). The fifth peak with small intensity is associated to $-\mathrm{COOH}$ (carboxyl groups).

"Graphitic" does not mean that a graphite-like structure was formed. To obtain this structure the $\mathrm{T}_{\mathrm{R}}$ was too low [60]. On the other hand, the electrons in $\mathrm{HC}$ are also delocalized, as it is consisting of pseudo-aromatic furfural-rings. Therefore, "graphitic" is interpreted here as "part of a delocalized $\pi$-electron system".

Whereas, the presence of $\mathrm{C}=\mathrm{O}$ bonds seemed to increase after the $1^{\text {st }}$ recirculation at $200{ }^{\circ} \mathrm{C}$, it decreased after the $2^{\text {nd }}$. Contrary to this, the $2^{\text {nd }}$ recirculation at $240{ }^{\circ} \mathrm{C}$ initiated a slight increase again, which may be due to impurities of carboxylic acids and aldehydes from the PW, adsorbed on the HCs surface and which interfere with the measurement.
The decrease of the peak intensity of $\mathrm{C}-\mathrm{N}$ at $200{ }^{\circ} \mathrm{C}$, particularly after the $1^{\text {st }}$ recirculation, and a $\mathrm{pH}$ decrease imply the hydrolysis of proteins and the release of amino acids. However, after the $2^{\text {nd }}$ recirculation an increase was observed at this temperature, which can be also seen after the $1^{\text {st }}$ recirculation at 220 and $240{ }^{\circ} \mathrm{C}$ (see Fig. 6). These are the indications for Maillard reactions including the condensation of protein-based with saccharide-based compounds. The so-called Amadori rearrangement as well as ongoing condensation reactions to nitrogen containing heterocycles (see Fig. 2) could also be proven by GC-MS (see Table 4) [41, 51, 61, 62].

The XPS studies confirmed that the main structure of $\mathrm{HC}$ is aromatic, in the sense of delocalized $\pi$-electron systems. This is accounted for the intramolecular condensation of polysaccharide fragments and that lignin hydrolyse to primary char as well as the integration of secondary (saccharide-related), protein-related and lipid-related char via the condensation/ polymerization of their dehydration products. The best investigated reaction is the polycondensation of furfuraldehydes from initial lignocellulosic material [6, 63]. Figure 7 shows that the recirculation of $\mathrm{PW}$ has an effect at 200 and $220^{\circ} \mathrm{C}$ by increasing the $\mathrm{C}-\mathrm{C}$ and $\mathrm{C}-\mathrm{O}$ bonds characteristic for cellulose-type structures, while severe conditions at $240{ }^{\circ} \mathrm{C}$ and the $\mathrm{PW}$ recirculation caused an intensified degradation, as confirmed by the van Krevelen plot in Fig. 3 and FT-IR spectra in Fig. 5.

The $\mathrm{N} 1 \mathrm{~s}$ spectrum in Fig. 8 mainly shows five signal peaks, namely due to the species of pyridinic-N (399.4 eV) with the structure $\mathrm{C}=\mathrm{N}-\mathrm{C}$, amine-N (399.9 eV) with the structure C-N-R2 $(\mathrm{R}=\mathrm{C}, \mathrm{H})$, pyrrolic-N $(400.5 \mathrm{eV})$ with the structure $\mathrm{C}-\mathrm{N}-\mathrm{H}$, quaternary-N or graphitic-N (401.5 eV) and inorganic-N or chemisorbed-N (402.4 eV). Compared with the $\mathrm{HC}$ produced at $200{ }^{\circ} \mathrm{C}$, quaternary- $\mathrm{N}$ increasing from 14 to $22 \%$ replaced inorganic-N, which then decreased from around 9 completely on the surface of HC obtained at $240{ }^{\circ} \mathrm{C}$ in water. Quaternary- $\mathrm{N}$ means here, nitogen heterocycles with a delocalized $\pi$-electron system. Whereas, amine- $\mathrm{N}$ also showed a decreasing trend from around 34 to $30 \%$, indicating the hydrolysis of proteins by enhancing the $\mathrm{T}_{\mathrm{R}}$ as well as the next step of recirculation. Particularly, the percentage of pyridinic-N increased from around 18 to $22 \%$ in addition to pyrrolic- $\mathrm{N}$ with a slight increase by enhancing the $\mathrm{T}_{\mathrm{R}}$ (see Fig. 8). However, during $\mathrm{PW}$ recirculation pyridinic- $\mathrm{N}$ showed a decreasing trend by around $2 \%$ independent from the $\mathrm{T}_{\mathrm{R}}$. For pyrrolic- $\mathrm{N}$ an increasing trend by around $5 \%$ could be seen, though not for the recirculation at $240{ }^{\circ} \mathrm{C}$. The $2^{\text {nd }}$ recirculation seems to have a general negative effect on the evolution of quartenary-N, justifying either the degradadtion of not stable nitrogen heterocycles resulted from malting of BSG or not completed Maillard reactions even at $240{ }^{\circ} \mathrm{C}$. 

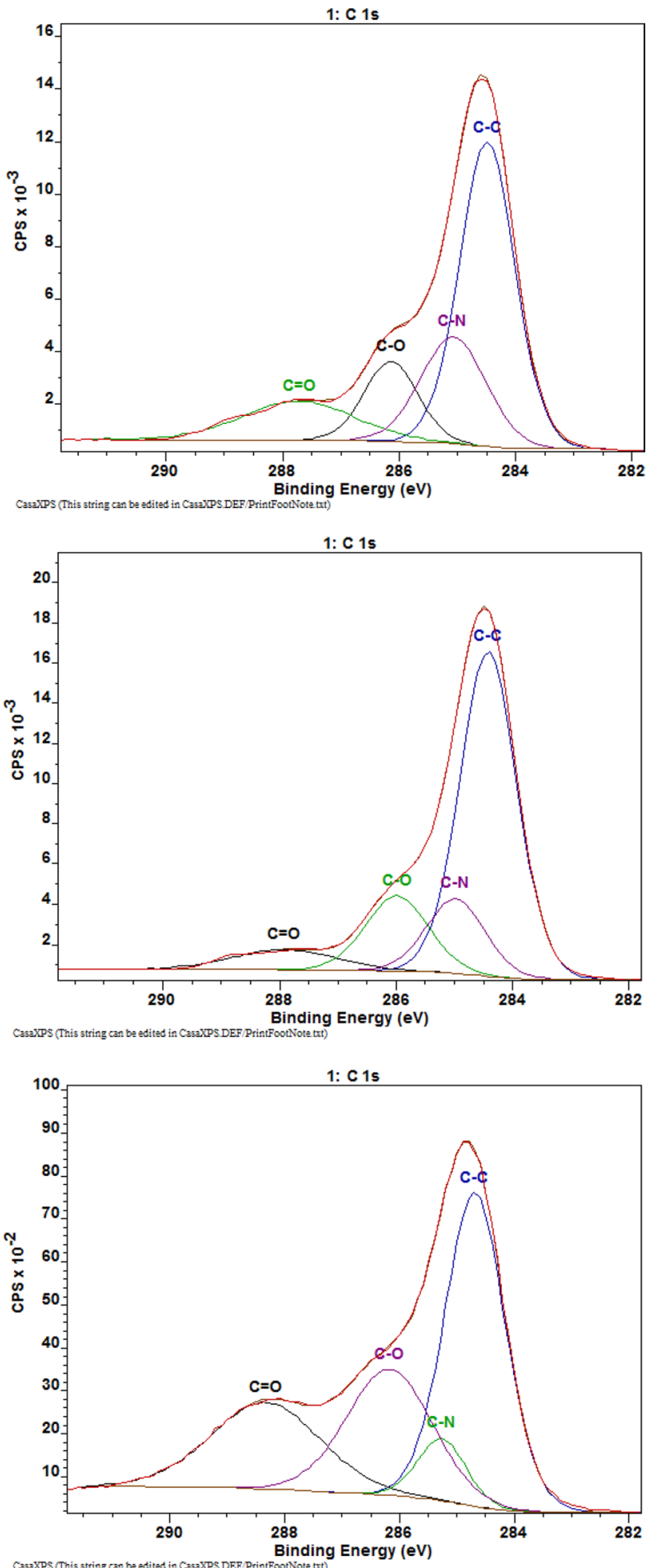

Fig. 6 X-ray photoelectron spectroscopy of hydrochars produced from Brewer's spent grains at $220{ }^{\circ} \mathrm{C}$ with water (top - initial $220{ }^{\circ} \mathrm{C}$ ), after the $1^{\text {st }}$ (middle $-1^{\text {st }} 220{ }^{\circ} \mathrm{C}$ ) and $2^{\text {nd }}$ recirculation of process water (bottom $-2^{\text {nd }} 220^{\circ} \mathrm{C}$ ). Only the ranges of the $\mathrm{C}-\mathrm{N}$ and $\mathrm{C}-\mathrm{O}$ bonds are shown

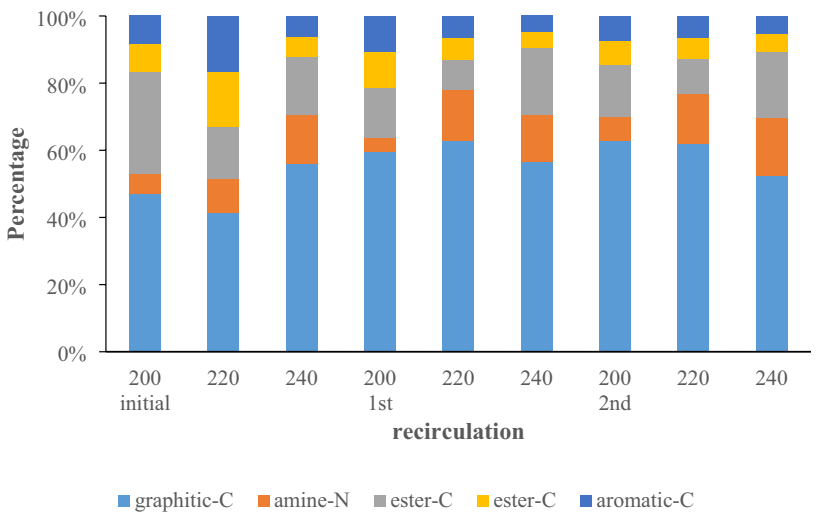

Fig. 7 X-ray photoelectron spectroscopy of hydrochars produced from Brewer's spent grains at 200,220 and $240{ }^{\circ} \mathrm{C}$ with water and after one or two recirculation steps of process water focusing on carbon structures

\section{Effect of Temperature and Recirculation Steps on the Composition of the Process Water}

The $\mathrm{T}_{\mathrm{R}}$ and the $\mathrm{pH}$ played a crucial role due to changing the balance of the various reaction pathways including Maillard reactions. The $\mathrm{T}_{\mathrm{R}}$ was varied from 200,220 to $240{ }^{\circ} \mathrm{C}$. As carboxylic acids were formed during $\mathrm{HTC}$, the $\mathrm{pH}$ value decreased by recirculation of the PW from the last HTCrun $[6,64]$.

The main components of the biomass were hydrolysed and the solved consecutive intermediates showed further reactions. Therefore, the dissolved compounds were important key compounds for the further chemical reactions occuring. These intermediates were also precursors for char formation. A selection of this key compounds is shown in Fig. 9. Here the origin of key compounds may be identified by remaining structure elements.

Lignin includes phenol rings, which could not be degraded under the conditions applied here [65]. Therefore, phenols are consecutive products of lignin hydrolysis. As phenols are weak acids, they can react with ammonia or amines, e.g. to form aminophenols (see Table 4).

Polysaccharides were hydrolysed and the glucose/ fructose rings are splitted by reverse aldol addition (see Fig. 1). It is the starting point for the formation of several oxygenrich compounds, some of which can be found in Fig. 9. The products are not specific, because similar or the same compounds from the $3^{\text {rd }}$ generation onwards can be formed via the decomposition of glycerol, originated from lipids and via Strecker degradation from amino acids/ proteins (see Fig. 1). Via Diels-Alder reaction aromatic compounds can be formed from polysaccharide-based compounds [66]. There are interactions with key compounds mainly from protein degradation: Amino acids form amides and subsequently Maillard reactions result in nitrogen heterocyclic compounds 


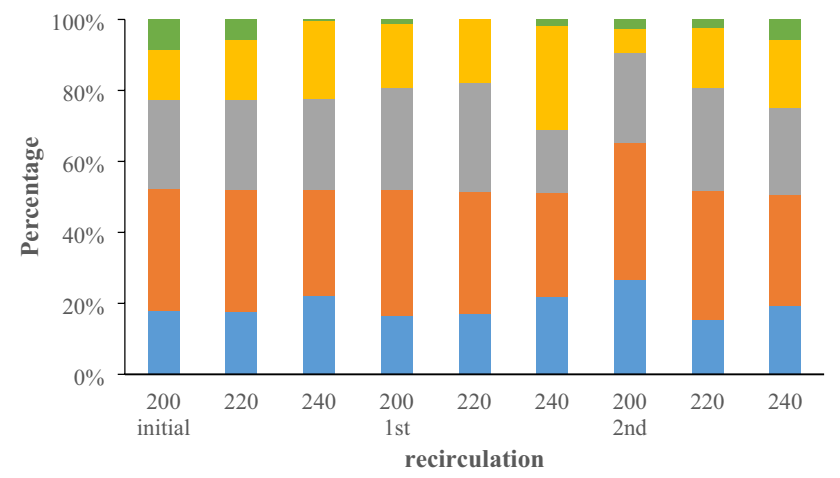

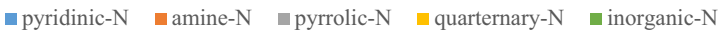

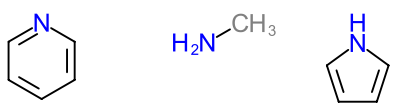<smiles></smiles>

$\mathrm{NH}_{4}^{+}$

Fig. 8 X-ray photoelectron spectroscopy of hydrochars produced from Brewer's spent grains at 200,220 and $240{ }^{\circ} \mathrm{C}$ with water and after two recirculation steps of process water regarding nitrogen containing structures. Examples for the different nitrogen species are also presented

(see Fig. 2, 9), whereas dicarbonyl-compounds can be oxidizing agents in a Strecker degradation (see Fig. 1).

Consecutive products of protein degradation often bind $\mathrm{N}$-atoms, these are amides, nitrogen heterocyclic compounds via Maillard reactions and ammonia or amines via hydrolysis, Strecker degradation or decarboxylation. In addition

Table 4 Qualitative analysis by Gas-Chromatography with Mass Spectrometry Detection for exploitation of the not detectable species in the Dissolved Organic Carbon of process waters obtained from after elimination of ammonia or an amine, oxygen-rich compounds may be produced (see Fig. 6, 7). The consequence was on the one hand a decreasing $\mathrm{N}_{\text {eff }}$ (see Eq. 13) independent on the $T_{R}$ as well as the recirculation step and on the other hand an increasing $\mathrm{N}_{\text {eff-rPW }}$ (see Eq. 14). The latter follows the priniciple: The higher the $T_{R}$ as well as proceeded the recirculation step, the higher the $\mathrm{N}_{\text {eff-rPW. }}$ More in detail, 88 and $91 \%$ of the dissolved nitrogen of rPW could be recovered at $240{ }^{\circ} \mathrm{C}$ (see Table S2).

Lipids are hydrolysed and glycerol and fatty acids are the consecutive products. Glycerol can further react to propenal and other compounds. The fatty acids may decarboxylate to aliphatic compounds. Unsaturated fatty acids can be easier splitted at the double bond than saturated ones. Key compounds of lipid degradation can be identified by aliphatic chains.

The decarboxylation of acids of any kind leads to $\mathrm{CO}_{2}$, the hydrolysis of hydrogen-sulphur-groups of proteins results in $\mathrm{H}_{2} \mathrm{~S}$. The total gas formation was considerably small and therefore neglected in this study.

The discussion of the following sections is based on the reaction scheme created by Wüst et al. [6] and the simplified sheme in Fig. 9. As shown in the HPLC-chromatograms (see Fig. S4, S5) hydrolysis of polymers and oligomers as $1^{\text {st }}$ generation reactions mostly took place after $2 \mathrm{~h}$ of $\mathrm{t}_{\mathrm{R}}$, which means that $2^{\text {nd }}$ followed by $3^{\text {rd }}$ and $4^{\text {th }}$ generation reactions occur. For a better comprehension, the authors categorized reactions such as the dehydration and reverse-aldol condensation (see Fig. 1,9) as

Hydrothermal Carbonization of Brewer's spent grains at 200, 220 and $240{ }^{\circ} \mathrm{C}$ with water and after one or two recirculation steps

\begin{tabular}{|c|c|c|c|c|c|c|c|c|c|c|}
\hline \multirow[t]{2}{*}{ Retention time } & \multirow[t]{2}{*}{ Compound name } & \multicolumn{9}{|c|}{ Sample name } \\
\hline & & Initial-200 & $1^{\text {st }}-200$ & $2^{\text {nd }}-200$ & Initial-220 & $1^{\text {st }}-220$ & $2^{\text {nd }}-220$ & Initial-240 & $1^{\text {st }}-240$ & $2^{\text {nd }}-240$ \\
\hline 14.81 & pyrazine, methyl- & - & - & - & + & + & + & + & ++ & ++ \\
\hline 16.38 & 2-propanone, 1-hydroxy- & ++ & ++ & ++ & + & + & + & - & - & - \\
\hline 15.62 & 1.2-butanone, 3-hydroxy- & ++ & ++ & ++ & + & + & + & + & - & - \\
\hline 19.10 & 2-cyclopenten-1-one, 2-methyl- & - & - & - & - & + & - & - & + & + \\
\hline 22.16 & acetic acid & +++ & +++ & +++ & +++ & +++ & +++ & +++ & +++ & +++ \\
\hline 25.73 & propionic acid & + & + & + & + & + & + & + & ++ & ++ \\
\hline 27.33 & furan, 2-pentyl- & ++ & ++ & ++ & ++ & ++ & ++ & - & - & - \\
\hline 30.78 & butanoic acid, 3-methyl- & - & - & - & - & - & - & + & + & + \\
\hline 34.86 & acetamide & - & - & - & + & + & - & + & + & + \\
\hline 38.19 & phenol, 2-methoxy- & - & - & - & - & + & - & + & ++ & ++ \\
\hline 44.78 & 2-pyrrolidinone & + & + & + & + & + & + & ++ & ++ & ++ \\
\hline 52.77 & phenol, 2,6-dimethoxy- & - & - & - & - & - & - & + & + & + \\
\hline 54.02 & phenol, 3-amino- & - & - & - & - & - & - & + & ++ & + \\
\hline 55.20 & pentanoic acid, 4-oxo- & ++ & ++ & ++ & ++ & ++ & ++ & ++ & ++ & ++ \\
\hline 58.33 & 3-pyridinol, 6-methyl- & ++ & ++ & ++ & ++ & ++ & ++ & ++ & ++ & ++ \\
\hline 59.34 & 3-pyridinol & +++ & +++ & +++ & +++ & +++ & +++ & +++ & +++ & +++ \\
\hline
\end{tabular}

Relative intensity [\%]: $+\leq 10.000 .000 ; 10.000 .000 \geq++\leq 100.000 .000 ;+++\geq 100.000 .000$ 


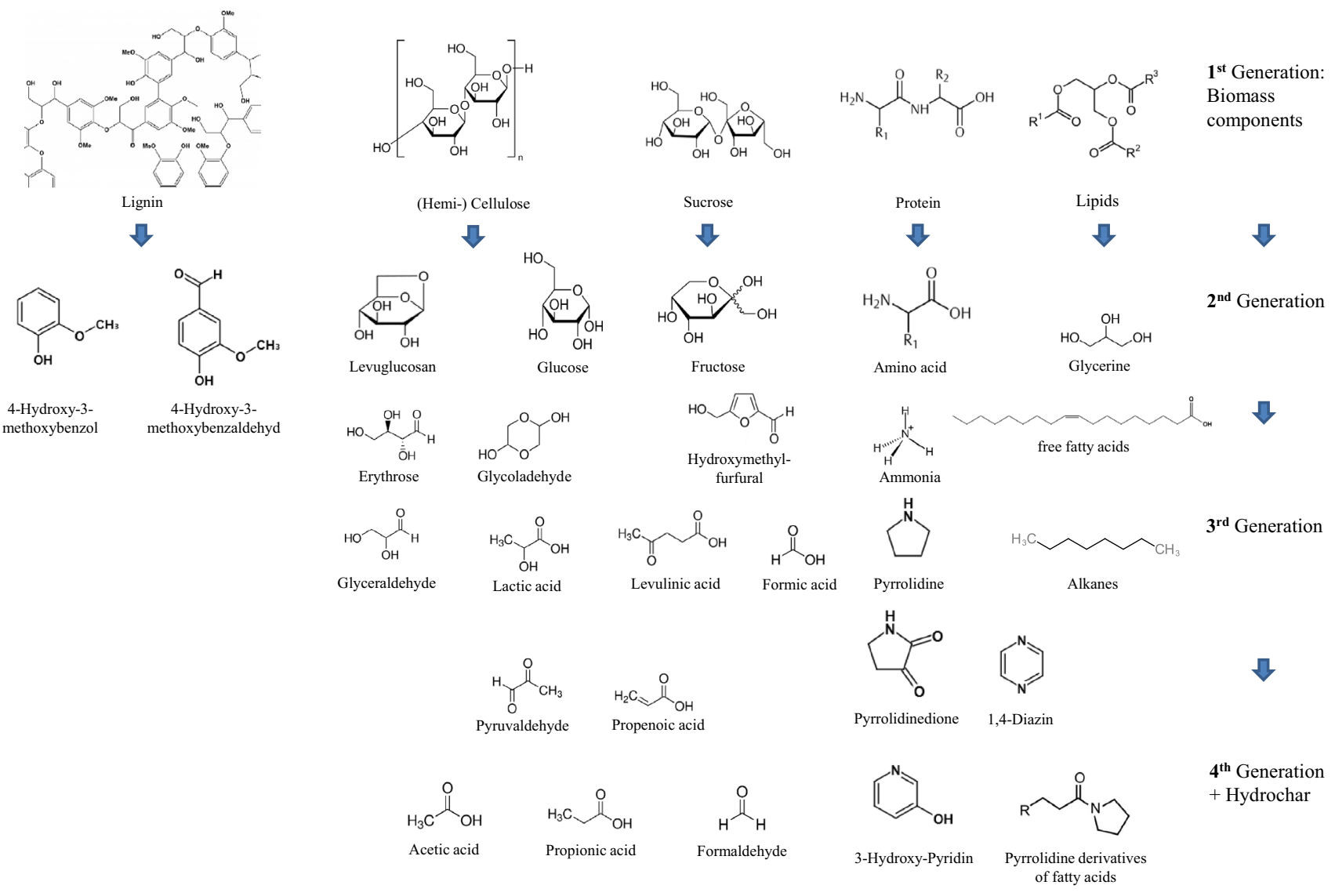

Fig. 9 Scheme of reaction products detected in the process water after hydrothermal carbonization of lignocellulosic biomass classified into four generations depending on their accumulation

$2^{\text {nd }}$ generation and rehydration, oxidation and subordinated reverse-aldol condensation and addition as $3^{\text {rd }}$ generation as well as condensation and polymerization toward humin or $\mathrm{HC}$ formation as $4^{\text {th }}$ generation reactions with according products (see Figs. 2, 9). This leads to the following groups of products according to several research groups [6, 51, 67]: a) $\mathbf{1}^{\text {st }}$ generation: starch, (hemi-) cellulose and its oligosaccharide fragments as well as lignin, protein, lipid, sucrose; b) $2^{\text {nd }}$ generation: fructose, levoglucosan, glucose, erythrose, glycolaldehyde, (di-)hydroxyacetone, pyruvaldehyde, glyceraldehyde, HMF, furfurylalcohol, furfural, oxalic acid, aspartic acid, serine, glycine, alanine, glycerine, vanilin, methoxyphenol, dimethoxyphenol, methyl-phenol, dimethyl-phenol, catechol, ammonia; c) $3^{\text {rd }}$ generation: pyruvic acid, glycolic acid, acetic acid, propenoic acid, lactic acid, acetaldehyde, formic acid, levulinic acid, 1,2,4-benzenetriol, methylfurfural, methanol, ethanol, fumaric acid, malic acid, succinic acid, esters, alkanes and alkenes, amides, pyrrolidinedione, pyrrolidine, pyrrolidinone, pyrazine; d) $4{ }^{\text {rd }}$ generation: acetic acid, propionic acid, formaldehyde, 2,5-dioxo-6-hexanal, pyridinol, and pyrrolidine derivatives of fatty acids. Not every compound could be quantified by HPLC, several ones are only identified and qualtitatively determined by GC-MS (see Table 4).

\section{Carbohydrate-based Reaction Products}

The results from liquid chromatography such as HPLC were validated by Gaschromatography (GC) with flame-ionization (FI) and mass spectrometry (MS) particularly for ethanol toward propionic acid, because ethanol may co-elute with the $\mathrm{C}_{3}$-acids propionic acid or propenoic acid $(\mathrm{RT}=18.3$ $-19.3 \mathrm{~min}$ ) depending on their concentration on the applied HPLC column (see Fig. S5). Since propionic acid could be verified by GC-MS (see Table 4), the assumed designation of Wüst et al. [6] and the evaluation of Arauzo et al. [23] for this peak was correct. Figure 8 shows the amount of (poly) saccharide consecutive products by HPLC. From this, the reaction pathways could be identified.

Firstly, the hydrolysis of polymers and oligomers such as (hemi-) cellulose (see Fig. 9), starch and sucrose to the monomers glucose and fructose increased with $T_{R}$. This way, 
glucose is formed and then compounds like the detected 2-methyl, 2-cyclopenten-1-one, a consecutive product of glucose [68] or Carboxymethyl-Cellulose [69]. Although, this compound was standardly formed under alkaline conditions [70] or extremely high pressures [71], it could be detected after the $1^{\text {st }}$ recirculation at $240{ }^{\circ} \mathrm{C}$. The more reactive furfural and HMF could only be found in very low amount, because of its polycondensation to form HC [72]. However, it cannot be excluded that the furfurals and other compounds were also oxidized to acetic acid. Acetic acid is a very inert compound, which needed high temperature to be degraded [73]. The carbon percentage of the $3^{\text {rd }}$ generation product mostly resulted from the reverse-aldol condensation (see Fig. 1, 7) of fructose and glucose. This reaction pathway of glucose could be verified by the presence of glycolaldehyde. The latter is the direct product of the reverse-aldol splitting [74]. Whereas, fructose was dehydrated to HMF and decarbonylated to furfurylalcohol, it reacted in parallel via retro-aldol condensation. The products 1,3-di-hydroxy2-propanone or hydroxyacetone (see Table 4 and Fig. 9) in addition to glyceraldehyde were tranformed into each other via the Keto-Enol Tautomerism (see Fig. 1). The Keto-Enol Tautomerism is also the way to form fructose from glucose, therefore the same compounds could be formed from glucose. However, another source of hydroxyacetone might also be lipids such as triglycerides, which were hydrolysed to glycerol and fatty acids [31]. The oxidation of glycerol resulted in hydroxyacetone.

Pyruvaldehyde was formed via dehydration from HA or glyceraldehyde [74]. It reacted further on via its rearrangement and the $\mathrm{H}_{2} \mathrm{O}$-addition to lactic acid [75]. Lactic acid was finally dehydrated and hydrogenated to propionic acid [76], which was definitely found during the $1^{\text {st }}$ and $2^{\text {nd }}$ recirculation at $240{ }^{\circ} \mathrm{C}$.

Whereas, glycolic acid could constantly be detected with the same carbon percentage, pyruvic acid was not detected after the $2^{\text {nd }}$ recirculation at 220 and $240{ }^{\circ} \mathrm{C}$. Perhaps it reacted to acetone or propionic acid. Formaldehyde reacted further via cross-disproportionation to formic acid and methanol [77], the authors showed an excess of formic acid related to the molar ratio with levulinic acid $[6,78]$. Both levulinic acid and formic acid are consecutive products of HMF, and are formed in 1:1 ratio by this reaction pathways. Values different from this ratio indicate additional reaction pathways. Levulinic acid was most probably completely decarboxylated or oxidized rather than embedded in HC [79, 80]. HMF reacts via Diels-Alder-addition to 1,2,4-benzenetriol $[76,81,82]$. Acetone is assumed to be formed via the reverse aldol condensation of pyrualdehyde [76].

Finally, the DOC balance could be closed up to $58 \mathrm{C} \%$ $\left(1^{\text {st }}-200{ }^{\circ} \mathrm{C}\right)$ by means of the optimized HPLC method developed in Wüst et al. [6] and the combination with the methods
Fig. 10 Carbon percentages of detected carbohydrate-based reaction products in the process waters from hydrothermal carbonization experiments with Brewer's Spent Grains in distilled water (initial) as well as recirculated processs water $\left(1^{\text {st }}\right.$, $2^{\text {nd }}$ recirculation step) related to the dissolved organic carbon (DOC)

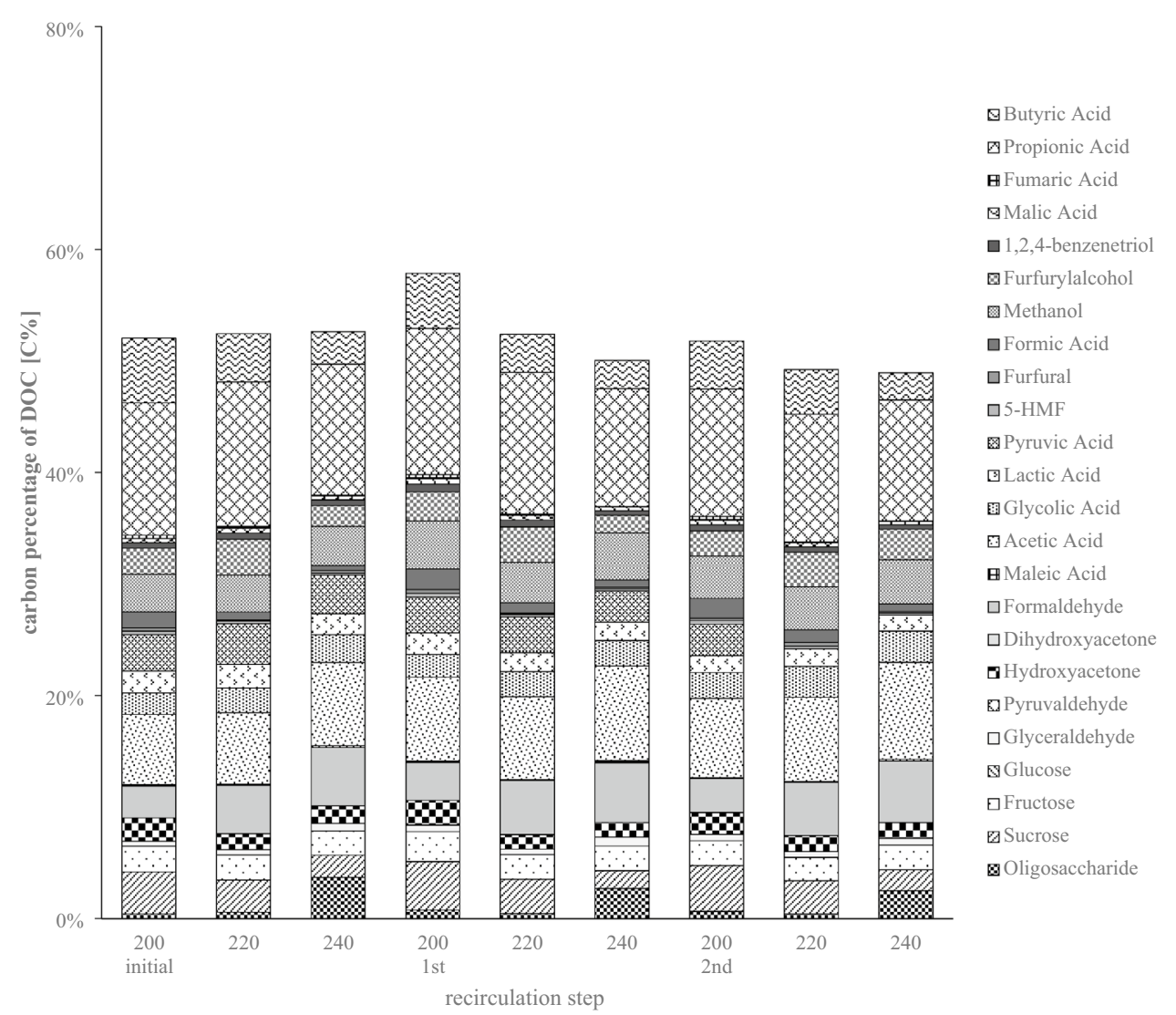


Fig. 11 Carbon percentages of detected lignin related reaction products in the process waters from hydrothermal carbonization experiments with Brewer's Spent Grains in water (initial) as well as recirculated processs water $\left(1^{\text {st }}+2^{\text {nd }}\right.$ recirculation step) related to the dissolved organic carbon (DOC). Syringol $=2,6$-dimethoxyphenol, 4-Hydroxy-3-methoxybenzaldehyd $=$ vanilin, 2-methoxy-phenol = guaiacol, 2-methyl-phenol $=0$-cresol, 1,2-dihydroxybenzene $=$ catechol
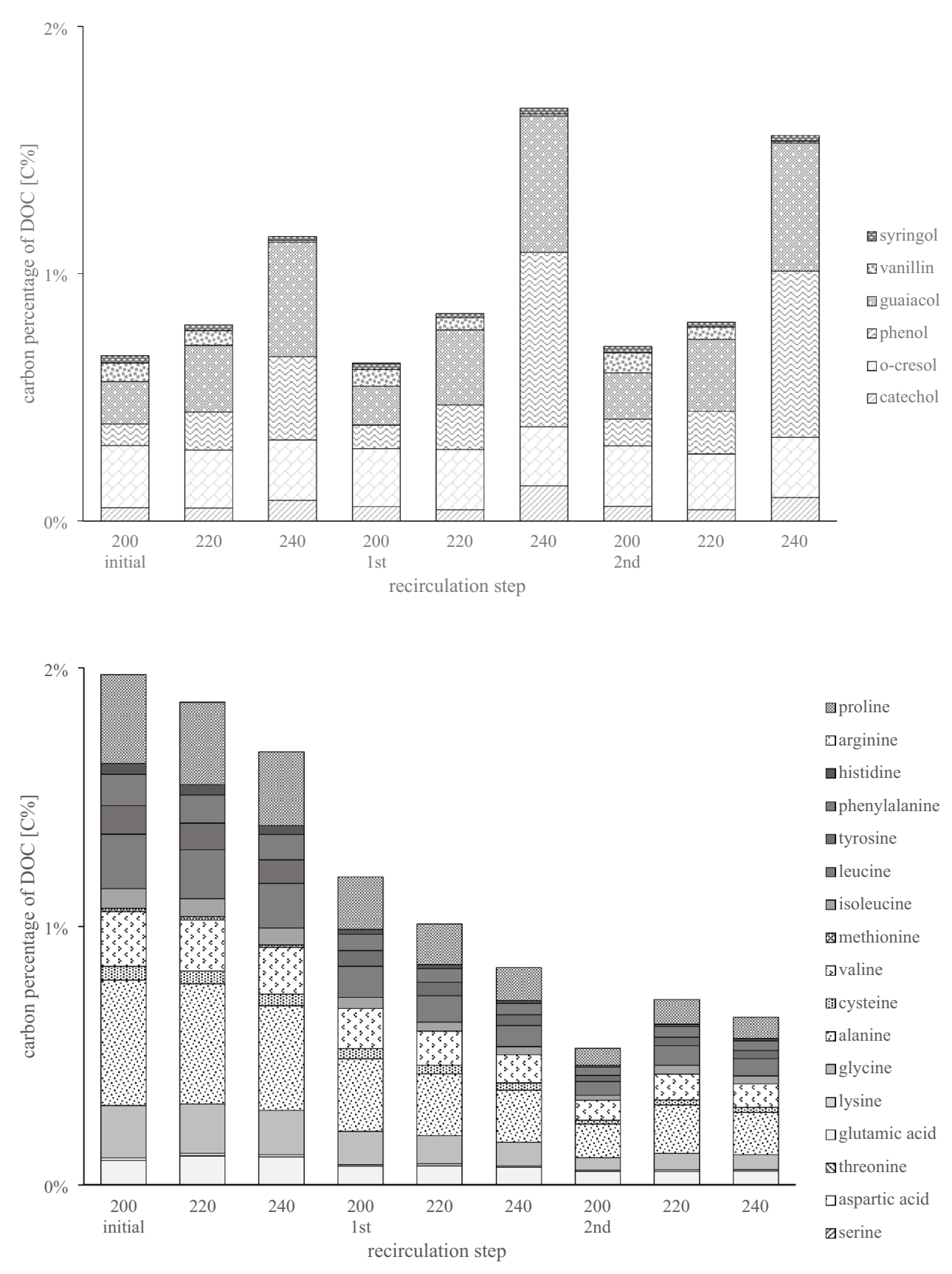

Fig. 12 Carbon percentages of detected protein-related reaction products in the process waters from hydrothermal carbonization experiments with Brewer's Spent Grains in water (initial) as well as recirculated processs water $\left(1^{\text {st }}\right.$ and $2^{\text {nd }}$ recirculation $)$ related to the dissolved organic carbon (DOC) for GC-MS and/ or -FID. The DOC balance (see Fig. 10) additionally showed that as from $220{ }^{\circ} \mathrm{C}$ the $1^{\text {st }}$ recirculation step entailed an increased lack of the DOC balance, which could be seen by an increased incidence of protein-, ligninand lipid-related compounds (see Figs. 10, 11, 12). Furthermore, these authors observed that the larger the particle size the better the DOC balance could be closed, namely up to $40 \mathrm{C} \%$ resulted from the HTC with the 500-850 $\mu \mathrm{m}$ particle size fraction in water. In this study, the particle size fractions larger than $500 \mu \mathrm{m}$ were the most present [6].

In summary, a recirculation mainly had the effect of a longer $t_{R}$ and higher acidic catalysis. As more reactive compounds reacted, their concentration decreased. A shift to $3^{\text {rd }}$ generation products was observed in the liquid phase (see Fig. 9, 10).

This had also a consequence for the solid phase. As shown in XPS spectra, the presence of $\mathrm{C}=\mathrm{O}$ bonds seemed to increase after the $1^{\text {st }}$ recirculation at $200{ }^{\circ} \mathrm{C}$, but they decreased after the $2^{\text {nd }}$. In contrary, the $2^{\text {nd }}$ recirculation at $240{ }^{\circ} \mathrm{C}$ produced an increase again, which can be explained by the adsorption of carboxylic acids and aldehydes from the PW on the HCs surface and consequently the interference of the measurement. The same was observed in FT-IR spectra. 


\section{Effect on Lignin-based Reaction Products}

It can be assumed that phenolic compounds from lignin (see Fig. 9) contribute to the total 'not detected' species, but only to a low extent up to $1.7 \%$ due to a moderate hydrolysis of the lignin [47]. Additionally, it can be noted that the C-percentage of the detected phenols ranged from 0.6 to $0.8 \%$ for the HTC with water and the $1^{\text {st }}$ recirculation at 200 and $220{ }^{\circ} \mathrm{C}$, but increased up to $1.2 \%$ (initial), $1.7 \%\left(1^{\text {st }} \mathrm{rec}\right)$ and $1.6 \%\left(2^{\text {nd }} \mathrm{rec}\right)$ after a HTC at $240{ }^{\circ} \mathrm{C}$. Consequently, the recirculation might have increased the total $t_{R}$, and also the higher acid concentration might have supported the hydrolysis of lignin. However, the effect is very low, which shows the low reactivity of lignin. $\mathrm{Hu}$ et al., Dinjus et al. and Barbier et al. described the lignin decomposition through ether bond cleavage at temperatures between 200 and $280{ }^{\circ} \mathrm{C}$, followed by the formation of monomers that, in turn, reacted with hydrogen from carbohydrates to produce monomeric phenolic compounds. Then, the applied $T_{R}$ are not enough to cleave stronger bonds like $\mathrm{C}-\mathrm{C}$ bonds; therefore, the process water contains less degradation products [83-85]. The compound distribution measured for the process waters was in agreement with the findings of Poerschmann et al. [86]. As these researchers detected vinylguaiacol (decarboxylation product of ferulic acid), phenylethyl alcohol, 4-OH-benzylalcohol, vanillin, salicylaldehyde, 2-methoxy-phenol or guaiacol as well as phenol [87] as hydrolysis products, it might be the case in this study. For this reason, these compounds i.e. guaiacol-type monomers have to be considered as leached from the new BSG taken for the $1^{\text {st }}$ and $2^{\text {nd }}$ recirculation [88] as well as released from degradation of lignin or similar polyphenolic polymers. Further degradation products of the lignin fraction (see Table 1) are catechol, 2-methyl-phenol or o-cresol, 2,6-dimethylphenol or syringol, whose carbon percentages increased due to further recirculation, but mainly by enhancing the $\mathrm{T}_{\mathrm{R}}$ (see Fig. 11).

As the lignin fraction was low, and was only partly hydrolysed, the phenol content was accordingly low. Unfortunately, the concentration of phenols is important in view of an aerobic or an anaerobic treatment of PW [89]. It is very important that a recirculation only slightly increases or decreases the amount of phenols in the PW. The carbon percentage related to $100 \%$ DOC remained nearly constant (see Fig. 11), despite the input of new hydrolysable lignin every HTC-run. Ryu et al. as well as Koch and Pein reported that these phenolic compounds together with furfural-like compounds are involved in aldol condensation/ addition reactions towards the formation of the so-termed secondary char $[90,91]$.

The work of Jung et al. shows that during HTC a first liquid phase is formed [92]. A hypothesis might be that the second liquid phase absorb the phenols. As $\mathrm{HC}$ incorporated pseudo-aromatic furfural rings, this could not be verified or falsified by XPS or FT-IR (see Fig. 5, 6, 7, 8). It was not possible to clearly distinguish between aromatic and pseudoaromatic structures by these methods for structural analysis.

\section{Protein-based Reaction Products}

As already mentioned Maillard reactions play a crucial role towards the formation of HC. Figure 2 is a very simplified version of a complex reaction network [62]. The products are nitrogen containing heterocycles and polymers known as melanoidins [67]. Melanoidins were identified after hydrothermal conversion of a binary mixture of glucose and glycine in several studies, and were responsible for the formation of a brown stable emulsion [93].

By comparison with the results from Maillard reactions of initial model matrices as well as biogenic wastes from food processing with a $\mathrm{pH}$ equal or smaller than 7 , as well as under ambient $[62,94]$ and hydrothermal conditions [61, $62,93,95-100]$, three reaction stages could be identified for this study [41]. The simplified three stages are:

(1) In the initial phase more complex amino acids are decomposed to simpler ones and the condensation of amino acids via the carbonyl group of reduced saccharides takes place (see Fig. 2) [61, 101]. In addition amino acids further react by elimination of ammonia or carbon dioxide.

(2) The subsequent rearrangement and breakdown of the Amadori compound (see Fig. 2) lead to a reaction cascade involving saccharide dehydration and fragmentation, deamination and Strecker degradation [102].

(3) The interaction of breakdown products of low molecular weight with amino groups via aldol condensation as well as aldehyde-amine condensation result in $\mathrm{N}$-containing polymers, known as melanoidins [41, 62].

To identify the role of the Maillard reaction, a closer look at the reaction of proteins and amino acids is necessary:

If one considers the DOC balance illustrated in Fig. 12, it is obvious that enhancing the $T_{R}$ has a small effect on the reactivity of amino acids in this range, particular for the main representers such as alanine, glycine, leucine, etc. However, the recirculation latestly after the $2^{\text {nd }}$ step more than halfed their C-percentage. This means that the reaction rate increases by recirculation. The reason is likely that with the PW consecutive products of carbohydrates were transferred into the reactor and reacted with amino acids.

Generally, amino acids differ only in their nature of side chains $(\mathrm{R})$, which determines their reactivity. In solution, it is the nature of their amino acid $\mathrm{R}$ group that dictates the structure-function relationships of peptides and proteins. 
Accordingly, they were classified into amino acids with hydrophobic non-polar aliphatic, hydrophobic aromatic, hydrophilic aromatic, hydrophilic aliphatic, or carrying negatively or positively charged $\mathrm{R}$ groups [96]. As consequence of their different reactivity, the ratio to one another changed with temperature and recirculation step (see Fig. 12).

In the initial phase, the reaction of free amino acids with carbonyl compounds derived from carbohydrate degradation took place [103, 104]. As an example, the reverse aldol splitting of fructose or glucose provides pyruvaldehyde, which is able to react with the most inert amino acid proline [93]. During the reaction, proline underwent decarboxylation and was transformed into a structurally related aldehyde (Strecker aldehyde) containing one less carbon atom than its amino acid precursor. In parallel, aspartic acid and serine were completely consumed via decarboxylation or retro-aldol condensation and resulted in simpler amino acids such as alanine and glycine $[97,105]$. The amino acid alanine reacted further to lactic acid and ammonia. The latter reacted for example with acetic acid to acetamide (see Table 4) [106, 107]. Glycine was converted to glycolic acid [97]. An alternative pathway of amino acids is decarboxylation to the corresponding amine and subsequently the hydrolysis with the release of $\mathrm{NH}_{4}{ }^{+}$and formation of alcohols [108]. In addition, oxidation may occur via the Stecker degradation [103, 104, 109, 110]. As products 1-pyrroline generated from decarboxylation of proline, which in addition may react via Strecker degradation as reported in Hoffmann et al. [109]. The heterocyclic compounds were verified via GC-MSD (see Fig. 9 and Table 4).

In the $2^{\text {nd }}$ stage, dihydroxyaceton and 3-hydroxy-1.2-butanone (see Fig. 3) resulted on the one hand from the decomposition of carbohydrates or the Strecker degradation [104, 111]. Their amount decreased by incrementing the $T_{R}$ and repeating the recirculation. On the other hand, nitrogen heterocycles like 3-pyridinol are found. This proves Maillard type reactions and amide formation. Not the presence of these key compounds, but the decreasing amount of amino acids (see Fig. 12) showed an increasing rate of reactions, with temperature and steps of recirculations. The consumption of $\mathrm{NH}_{4}{ }^{+}$is visible within the $\mathrm{HTC}$ at $200{ }^{\circ} \mathrm{C}$ and the following recirculation steps (see Table $\mathrm{S} 3$ ), supporting this.

In the $3^{\text {rd }}$ stage several synthesis reactions occured. The carbonyl compounds from (poly)saccharides and amino acids (Strecker aldehydes) showed consecutive products with higher molecular weight. A good example is the degradation of glutamic acid, which may readily form heterocyclic amines with HMF (a melanoid intermediate), acrylamide with glucose or fructose [112] or 2-pyrrolidinone [113]. In the end, this leads to $\mathrm{N}$-containing HC.

As concluded by Heilmann et al., Maillard reactions effectively take place when saccharides, protein and lipid derivatives are involved [114].

\section{Lipid-based Reaction Products}

In general, fatty acids (see Fig. 10, S6) in addition to glycerol are produced by the hydrolysis of triglyceride molecules without any catalyst $[5,115]$. As an example, Tavakoli et al. oberved that the hydrothermal hydrolysis on squid wastes hydrolyzed the triglyceride molecules [116]. Nine fatty acids such as myristic acid, palmitoleic acid, palmitic acid, oleic acid, stearic acid, eicosapenaneoic acid (EPA), eicosenoic acid, docosahexaenoic acid (DsHA) and docosenoic acid (erucic acid) were found with a maximum yield at $240{ }^{\circ} \mathrm{C}$ for $40 \mathrm{~min}$, which Ravber et al. could also prove by treating sunflower seeds at the same $T_{R}$ but for $120 \mathrm{~min}$ [100]. The amount of fatty acids in the oil phase was found to be DsHA $>$ palmitic acid $>$ oleic acid $>$ EPA [117]. The yields of DsHA, EPA, and oleic acid after maximum values at 200-270 ${ }^{\circ} \mathrm{C}$ sharply decreased due to decomposition and degradation of double bonds.

In the BSG taken as feedstock for this study the following free fatty acids with a decreasing percentage were present: ethyl linoleate $(\mathrm{C} 18: 2 \mathrm{n} 6 \mathrm{c})>$ palmitic acid $(\mathrm{C} 16: 0)>$ oleic acid $(\mathrm{C} 18: 1 \mathrm{n} 9 \mathrm{c})>\alpha$-linolenic acid $(\mathrm{C} 18: 3 \mathrm{n} 3)>$ stearic acid $(\mathrm{C} 18: 0)>$ gondoic acid $(\mathrm{C} 20: 1)>$ tertadecyclic acid (C14:0) > lignoceric acid (C24:0) > behenic acid (C22:0) and others in traces, which mostly meet the fatty acid pattern of common BSG [87]. Whereas, the released fatty acids from C4:0 to C18:0 as well as those above C24:0 are mostly stable during the $\mathrm{HTC}$ at 200 and $220{ }^{\circ} \mathrm{C}$, the remaining ones were subjected to degradation to $\mathrm{CO}_{2}$ and its alkenes [118], particularly at $240{ }^{\circ} \mathrm{C}$. In general, saturated fatty acids, as the mentioned compounds, should be more stable than the unsaturated. The double bonds enables further reaction leading for example to a splitting of these compounds.

Fatty acids like other carboxylic acids may react via decarboxylation. Despite this, the reactivity is low. There is in addition no possibility to be included in the bulk of HC. Consequently, fatty acids in addition to carboxylic acids accumulate in the PWs and contribute to the increasing DOC and COD by further recirculation steps according to what reported elsewhere $[17,22,119,120]$. However, it could be proven that 2-pentylfuran (see Table 4) resulted from the reaction probably of furfural with linoleic and arachidonic acid, via 2,4-decadienal [121]. This is an example of the interaction of lipid-based with carbohydrate-based compounds. In addition, fatty acids may form amides by reaction with amines or ammonia.

\section{Formation of $\mathrm{N}$-containing Hydrochar}

In general, the increase of the $T_{R}$ results into the decomposition of the easily degradable fractions of BSG such as hemicellulose, the amorphous fraction of the cellulose and the non-recalcitrant fraction of the starch as well as proteins 
and lipids. The resulting fragments were solubilized into the PW. In $2 \mathrm{~h}$ of $t_{R}$ the solubilized organic matter was decomposed further on. Therefore, reduced saccharides and amino acids even themselves as well as their reactive consecutive products, such as aldehydes and carboxylic acids, were prone to poly-condensate to a secondary char fraction $[6,26]$. Nevertheless, a stable structure consisting of carbon spheres (secondary char) formed by aldol condensation/ addition and $\mathrm{N}$-containing heterocycles (tertiary char) resulting from Maillard reactions embedded in an aromatic network (primary char) could not be visualized by SEM as assumed by Wüst et al. [6] and presented by Kannan et al. [25] (see Fig. S1).

Changes in the inorganic matter are due to the release of embedded salts during the degradation of the surrounding organic structures on the one side or removal of e.g. alkaline salts from the ash through a pH between 3.5 and 4 occur on the other side [122]. Whereas, a decreasing sulphur content accomplished by a decreasing content of hydrogen and oxygen (see Table 3) confirmed the hydrolysis of organic matter such as proteins [26].

This observation regarding the liquid phase helps to understand the observations in the solid phase. As mentioned in the beginning, in the case of BSG the $\mathrm{HC}$ formation is mainly a consequence of polymerisation/ polycondensation from solved intermediates. Since BSG contains amino, carboxylic, and thiol groups [49], it includes heteroatoms, which are incorporated in the intermediates and then in the HC. The ratios of N/C as well as N/S were calculated and given in Table 3 . The results showed that at $200{ }^{\circ} \mathrm{C}$, the N/C decreased by 0.16 and S/C increased by 0.001 relative to BSG. However, the amino acids in the PW partly hydrolysed forming ammonia and partly formed nitrogen compounds, being incorporated in the HC. These are mainly Maillard products, forming quaternary-N, pyridinic-N and pyrrolic-N in the HC (see Fig. 8). The ratios stay constant with changes due to temperature and steps of recirculation. Salts including nitrogen are solved [26]. The S/C-ratios of HCs were increased by 0.001 for all processing parameters in comparison to that one of BSG. Which means that the sulphur-compounds are more stable/ inert against hydrolysis than the nitrogen compounds. This also means that the formation of nitrogen doped HC is supported by recirculation.

For the following discussion the application of $\mathrm{HC}$ is decisive; either as energy carrier or precursor for e.g. electrode materials in supercapacitors. Under consideration of the $\mathrm{Y}_{\mathrm{HC}}$, which is the basis for the calcluation of the $\mathrm{EY}_{\mathrm{HC}}$ as well as the carbon contribution and the efficiency of PW recirculation $\left(\mathrm{C}_{\text {eff-rPW }}\right)$ in Fig. 4, the $\mathrm{HTC}$ at $220^{\circ} \mathrm{C}$ appeared as a good basis for the production of an energy carrier. Here the $\mathrm{Y}_{\mathrm{HC}}$ decrease and the increase of the heating value (HHV) compensate each other in the way that a high $\mathrm{EY}_{\mathrm{HC}}$ is reached (Table 3). The effect of recirculation is small.
Also negative effects like the increased ash content are small and acceptable in view of the advantages of recirculation. In addition, Wang et al. [123] supportively reported that a $\mathrm{HC}$ produced at $220^{\circ} \mathrm{C}$ from food waste emitted less $\mathrm{NO}$ emissions during combustion than a $\mathrm{HC}$ produced at 200 and $240{ }^{\circ} \mathrm{C}$ due to the presence of lower contents of pyridine- $\mathrm{N}$ and/ or quaternary-N (see Fig. 6). Additionally, this research group also found out that aromatic- and sulfate-S increased, in contrast to sulfoxide-S, which influences the emission of $\mathrm{SO}_{2}$ as well as the slagging index [28]. Slagging is not only positively influenced by the decrease and conversion of the sulphur compounds but also by the decrease of $\mathrm{Ca}$ and $\mathrm{Mg}$ salts in the $\mathrm{HC}$, produced at $220^{\circ} \mathrm{C}$ after the $2^{\text {nd }}$ recirculation (see Table S1).

The FR of HCs, which leads to an evaluation of their combustability, reaches its maximum at $240{ }^{\circ} \mathrm{C}$. Here, it is more than 2.8 times higher than the FR of the feedstock (see Table 3). Nevertheless, it might be associated to the energy input and larger loss of carbon into the $\mathrm{PW}$, in comparison to $220^{\circ} \mathrm{C}$.

For the evaluation, whether the process management results in outstanding characteristics of $\mathrm{HCs}$ for the production of a precursor for e.g. electrode materials in supercapacitors a new view to the results is necessary. Structural analysis concerning the nature of chemical bonds present in the carbonaceous bulk and surface by means of FT-IR and XPS had to be performed. Special consideration was paid to carbon and particularly nitrogen species, since they were of significance for improving the eletrochemical performance. In addition, the $\mathrm{CO}_{2}$ adsorption capacity of carbonaceous materials was improved by heteroatom inclusion [59].

The fact that the degradation of proteins took place by enhancing the $T_{R}$ and nitrogen containing heterocycles (e.g., pyrridine and pyrrole) are formed is also visible in the FT-IR spectra. The reactions of amino acids, like amide formation or its condensation with reduced sugars and aldehydes could particularly be proven by using PW as reaction medium [51]. Here, the addition of protein degradation products should enhance their reactions. It is distinctly realized from the FT-IR spectra that the variety of surface functional groups of $\mathrm{HCs}$ raised with recirculation, especially the $\mathrm{O}-\mathrm{H}, \mathrm{C}-\mathrm{H}$, $\mathrm{N}-\mathrm{H}, \mathrm{C}-\mathrm{N}, \mathrm{C}=\mathrm{C}, \mathrm{C}=\mathrm{O}$, and $\mathrm{C}=\mathrm{N}$, and was beneficial for later electrochemical and adsorption applications [59]. A simplified C- and N-related structure (bulk) and its surface functionalities might look like in Fig. 13.

These insights could be supported by the results of XPS (see Figs. 6-8). Hereby, it can be concluded that particularly at $240{ }^{\circ} \mathrm{C}$ Maillard reactions resulting in the condensation of protein-based decomposition compounds and carbohydratebased compounds are forced [51]. This is supported by the compositions of the solved organic compounds, dicussed above. Whereas, a $1^{\text {st }}$ recirculation at 200 and $220{ }^{\circ} \mathrm{C}$ resulted in a decrement of pyridinic- $\mathrm{N}$ and pyrrolic- $\mathrm{N}$ in 
Fig. 13 Symplified carbon and nitrogen related structure/ network (bulk) and its surface functionalities of hydrochar (HC) after process water recirculation at a $\mathrm{HTC}$ reaction temperature of $240{ }^{\circ} \mathrm{C}$

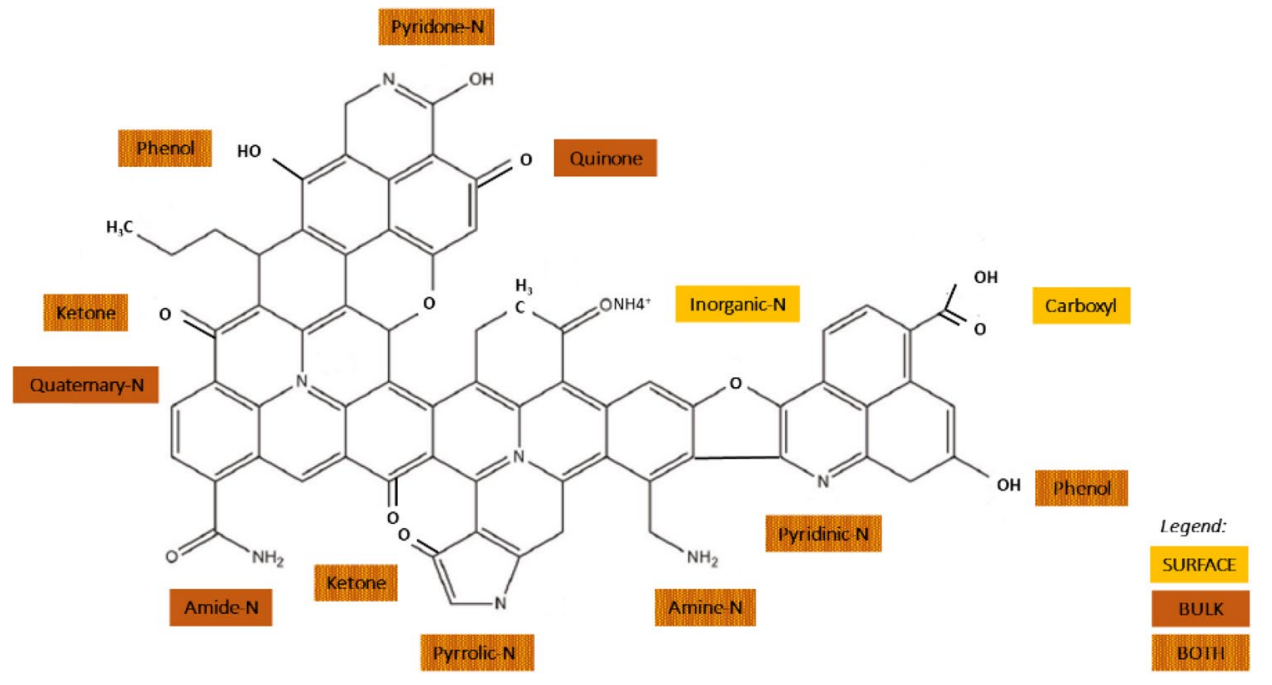

XPS (see Fig. 8), the $2^{\text {nd }}$ recirculation caused an increase compared with the initial HTC-run. At $240{ }^{\circ} \mathrm{C}$ the $1^{\text {st }}$ and $2^{\text {nd }}$ recirculation decreased the pyridinic- $\mathrm{N}$ but the pyrrolic-N firstly decreased and increased then again. The quaternary-N showed the reverse course, which confirmed the intensification of deamination and a release of $\mathrm{NH}_{4}{ }^{+}$(see Table S3) as well as the formation of "graphitic- $\mathrm{N}$ " at $240{ }^{\circ} \mathrm{C}$. While, as before mentioned, the percentage of inorganic- $\mathrm{N}$ decreased also due to the solubilization of salts as well as the hydrolysis of $\mathrm{NH}_{4}{ }^{+}$with the increment of $\mathrm{T}_{\mathrm{R}}$, latestly the $2^{\text {nd }}$ recirculation causes chemisorption of $\mathrm{NH}_{4}{ }^{+}$on oxygen containing functional groups again [124].

To sum it up, the FT-IR represents a more sensitive technique for the identification of nitrogen structures, particular of quaternary/ graphitic and amide character as well as carbon structures of quinone character in both, bulk and surface of HCs.

\section{Conclusion}

This research strategy in combination with the applied and further developed analytical methods help to identify the main decomposition pathways of the main constitutents of BSG including hydrolysis of polymers and oligomers as $1^{\text {st }}$ generation reactions, as well as dehydration and reversealdol condensation as $2^{\text {nd }}$ generation reactions, and rehydration, oxidation and subordinated reverse-aldol condensation and addition as $3^{\text {rd }}$ generation reactions, followed by condensation, acylation and polymerization toward humin or $\mathrm{HC}$ formation as $4^{\text {th }}$ generation reactions. By means of three different HPLC methods, the detection and quantification of oligo-, di- and monomers as well as ketones, aldehydes, carboxylic acids and alcohols in addition to amino acids and mainly methoxy-phenols, resulted from reactions of $1^{\text {st }}, 2^{\text {nd }}$ and $3^{\text {rd }}$ generation, delivered the basis for closing the DOC balance up to $60 \%$, which is a progress not reported elsewhere. However, the detection of $4^{\text {th }}$ generation products still dissolved have only been possible qualitatively and probably not complete as yet, which requires further development of GC methods. Nevertheless, the additional analyses of HCs by proximate and ultimate analyses as well as particular FT-IR as bulk-sensitive analysis allowed drawing the conlusion that $\mathrm{HCs}$ produced at $220^{\circ} \mathrm{C}$ despite recirculation of PW are suitable for the use as energy carrier. However, HCs produced at $240{ }^{\circ} \mathrm{C}$, particularly due to higher fraction of more stable carbon and nitrogen containing hetercocycles or rather aromaticitiy resulted from more progressed depolymerization followed by de-oxygenation and condensation reactions (Maillard reactions), are more suitable for the use as nitrogen doped carbonaceous materials or precursors for the production of electrode materials. Enhancing the $t_{R}$ as well as further recirculation steps could be an option to force further condensation reactions, because reactants were still be detectable after $120 \mathrm{~min}$. Finally, the positive effect will be a further reduction of the DOC or rather the COD and less problems regarding PW treatment or disposal. Furthermore, structural analysis for a better elucidation of the carbon and nitrogen related network will be pursued with a Thermogravimetric Analysis (NETZSCH-Gruppe, Selb, Germany) coupled with a Gaschromatography with Masspectrometric Detection (GC-MS - Agilent Technologies, Santa Clara, USA).

Acknowledgements We thank the chemical-technical assistants Armin Lautenbach and Veronika Holderied from the Institute of Catalysis Research and Technology of the Karlsruhe Institute of Technology (KIT-IKFT) as well as the scientific staff Ekatarina Ovsyannikova from the University of Hohenheim for their organizational and analytical support. Special thanks to the co-author Sonja Habicht, who supported the corresponding author at all times and with full commitment in his doctoral thesis and thus had an extremely positive influence on his education and consequently on this publication. We wish her all the best for her retirement. 
Funding Open Access funding enabled and organized by Projekt DEAL.

\section{Declarations}

Conflict of interest The authors declare that they have no conflicts of interest.

Open Access This article is licensed under a Creative Commons Attribution 4.0 International License, which permits use, sharing, adaptation, distribution and reproduction in any medium or format, as long as you give appropriate credit to the original author(s) and the source, provide a link to the Creative Commons licence, and indicate if changes were made. The images or other third party material in this article are included in the article's Creative Commons licence, unless indicated otherwise in a credit line to the material. If material is not included in the article's Creative Commons licence and your intended use is not permitted by statutory regulation or exceeds the permitted use, you will need to obtain permission directly from the copyright holder. To view a copy of this licence, visit http://creativecommons.org/licenses/by/4.0/.

\section{References}

1. Bergius FCR. Die Anwendung hoher Drucke bei chemischen Vorgängen und eine Nachbildung des Entstehungsprozesses der Steinkohle, von Dr. Friedrich Bergius,: W. Knapp; 1913.

2. Titirici, M.-M., Thomas, A., Antonietti, M.: Back in the black: Hydrothermal carbonization of plant material as an efficient chemical process to treat the CO2 problem? New J. Chem. 31, 787-789 (2007). https://doi.org/10.1039/b616045j

3. Kruse, A., Baris, D., Tröger, N., Wieczorek, P.: Scale-Up in Hydrothermal Carbonization. In: Titirici, M.-M. (ed.) Sustainable carbon materials from hydrothermal processes, pp. 341-353. Wiley, Chichester, West Sussex, United Kingdom (2013)

4. Houtman, C.J.: Emerging contaminants in surface waters and their relevance for the production of drinking water in Europe. J. Integr. Environ. Sci. 7, 271-295 (2010). https://doi.org/10. 1080/1943815X.2010.511648

5. Becker, R., Dorgerloh, U., Paulke, E., Mumme, J., Nehls, I.: Hydrothermal carbonization of biomass: major organic components of the aqueous phase. Chem. Eng. Technol. 37, 511-518 (2014). https://doi.org/10.1002/ceat.201300401

6. Wüst, D., Correa, C.R., Jung, D., Zimmermann, M., Kruse, A., Fiori, L.: Understanding the influence of biomass particle size and reaction medium on the formation pathways of hydrochar. Biomass Conv. Bioref. 10, 1357-1380 (2020). https://doi.org/ 10.1007/s 13399-019-00488-0

7. Paksung, N., Pfersich, J., Arauzo, P.J., Jung, D., Kruse, A.: Structural effects of cellulose on hydrolysis and carbonization behavior during hydrothermal treatment. ACS Omega 5, 12210-12223 (2020). https://doi.org/10.1021/acsomega.0c00737

8. Libra, J.A., Ro, K.S., Kammann, C., Funke, A., Berge, N.D., Neubauer, Y., et al.: Hydrothermal carbonization of biomass residuals: a comparative review of the chemistry, processes and applications of wet and dry pyrolysis. Biofuels 2, 71-106 (2011). https://doi.org/10.4155/bfs.10.81

9. Erdogan, E., Atila, B., Mumme, J., Reza, M.T., Toptas, A., Elibol, M., Yanik, J.: Characterization of products from hydrothermal carbonization of orange pomace including anaerobic digestibility of process liquor. Bioresour Technol. 196, 35-42 (2015). https://doi.org/10.1016/j.biortech.2015.06.115
10. Wirth B, Mumme J, Erlach B. Anaerobic Treatment of Waste Water Derived from Hydrothermal Carbonization: ETA-Florence Renewable Energies; 2012.

11. Wirth, B., Krebs, M., Andert, J.: Anaerobic degradation of increased phenol concentrations in batch assays. Environ Sci Pollut Res Int. 22, 19048-19059 (2015). https://doi.org/10. 1007/s11356-015-5100-8

12. Merzari F, Langone M, Andreottola G, Fiori L. Methane production from process water of sewage sludge hydrothermal carbonization. A review. Valorising sludge through hydrothermal carbonization. Critical Reviews in Environmental Science and Technology. 2019;49:947-88. doi:https://doi.org/10.1080/ 10643389.2018 .1561104$.

13. Lucian, M., Volpe, M., Merzari, F., Wüst, D., Kruse, A., Andreottola, G., Fiori, L.: Hydrothermal carbonization coupled with anaerobic digestion for the valorization of the organic fraction of municipal solid waste. Bioresour Technol. 314, 123734 (2020). https://doi.org/10.1016/j.biortech.2020.123734

14. Reza, M.T., Freitas, A., Yang, X., Coronella, C.J.: Wet Air Oxidation of Hydrothermal Carbonization (HTC) Process Liquid. ACS Sustainable Chem. Eng. 4, 3250-3254 (2016). https://doi. org/10.1021/acssuschemeng.6b00292

15. Stutzenstein, P., Weiner, B., Köhler, R., Pfeifer, C., Kopinke, F.-D.: Wet oxidation of process water from hydrothermal carbonization of biomass with nitrate as oxidant. Chem. Eng. J. 339, 1-6 (2018). https://doi.org/10.1016/j.cej.2018.01.080

16. Aida, T.M., Nonaka, T., Fukuda, S., Kujiraoka, H., Kumagai, Y., Maruta, R., et al.: Nutrient recovery from municipal sludge for microalgae cultivation with two-step hydrothermal liquefaction. Algal Res. 18, 61-68 (2016). https://doi.org/10.1016/j. algal.2016.06.009

17. Stemann, J., Putschew, A., Ziegler, F.: Hydrothermal carbonization: process water characterization and effects of water recirculation. Bioresour Technol. 143, 139-146 (2013). https:// doi.org/10.1016/j.biortech.2013.05.098

18. Kabadayi Catalkopru, A., Kantarli, I.C., Yanik, J.: Effects of spent liquor recirculation in hydrothermal carbonization. Bioresour Technol. 226, 89-93 (2017). https://doi.org/10. 1016/j.biortech.2016.12.015

19. Heidari, M., Salaudeen, S., Dutta, A., Acharya, B.: Effects of process water recycling and particle sizes on hydrothermal carbonization of biomass. Energy Fuels. 32, 11576-11586 (2018). https://doi.org/10.1021/acs.energyfuels.8b02684

20. Uddin, M.H., Reza, M.T., Lynam, J.G., Coronella, C.J.: Effects of water recycling in hydrothermal carbonization of loblolly pine. Environ. Prog. Sustainable Energy. (2013). https://doi. org/10.1002/ep.11899

21. Kambo, H.S., Minaret, J., Dutta, A.: Process Water from the Hydrothermal Carbonization of Biomass: A Waste or a Valuable Product? Waste Biomass Valor. 9, 1181-1189 (2018). https://doi.org/10.1007/s12649-017-9914-0

22. Chen, X., Ma, X., Peng, X., Lin, Y., Wang, J., Zheng, C.: Effects of aqueous phase recirculation in hydrothermal carbonization of sweet potato waste. Bioresour Technol. 267, 167-174 (2018). https://doi.org/10.1016/j.biortech.2018.07. 032

23. Arauzo, P.J., Olszewski, M.P., Wang, X., Pfersich, J., Sebastian, V., Manyà, J., et al.: Assessment of the effects of process water recirculation on the surface chemistry and morphology of hydrochar. Renewable Energy 155, 1173-1180 (2020). https://doi.org/ 10.1016/j.renene.2020.04.050

24. Zhuang, X., Huang, Y., Song, Y., Zhan, H., Yin, X., Wu, C.: The transformation pathways of nitrogen in sewage sludge during hydrothermal treatment. Bioresour Technol. 245, 463-470 (2017). https://doi.org/10.1016/j.biortech.2017.08.195 
25. Kannan, S., Gariepy, Y., Raghavan, G.S.V.: Optimization and characterization of hydrochar produced from microwave hydrothermal carbonization of fish waste. Waste Manag. 65, 159-168 (2017). https://doi.org/10.1016/j.wasman.2017.04.016

26. Xu, Z.-X., Song, H., Li, P.-J., He, Z.-X., Wang, Q., Wang, K., Duan, P.-G.: Hydrothermal carbonization of sewage sludge: Effect of aqueous phase recycling. Chem. Eng. J. 387, 123410 (2020). https://doi.org/10.1016/j.cej.2019.123410

27. Xu, Z.-X., Deng, X.-Q., Zhang, S., Shen, Y.-F., Shan, Y.-Q., Zhang, Z.-M., et al.: Benign-by-design N-doped carbonaceous materials obtained from the hydrothermal carbonization of sewage sludge for supercapacitor applications. Green Chem. 22, 3885-3895 (2020). https://doi.org/10.1039/D0GC01272F

28. Volpe, M., Wüst, D., Merzari, F., Lucian, M., Andreottola, G., Kruse, A., Fiori, L.: One stage olive mill waste streams valorisation via hydrothermal carbonisation. Waste Manage. 80, 224-234 (2018). https://doi.org/10.1016/j.wasman.2018.09.021

29. Fan, Y., Hornung, U., Dahmen, N., Kruse, A.: Hydrothermal liquefaction of protein-containing biomass: study of model compounds for Maillard reactions. Biomass Conv. Bioref. 8, 909-923 (2018). https://doi.org/10.1007/s13399-018-0340-8

30. Alhnidi, M.-J., Körner, P., Wüst, D., Pfersich, J., Kruse, A.: Nitrogen-containing hydrochar: the influence of nitrogen-containing compounds on the hydrochar formation. ChemistryOpen. 9, 864-873 (2020). https://doi.org/10.1002/open.202000148

31. Zanon Costa C, Falabella Sousa-Aguiar E, Peixoto Gimenes Couto MA, Souza de Carvalho Filho JF. hydrothermal treatment of vegetable oils and fats aiming at yielding hydrocarbons: a review. Catalysts. 2020;10:843. doi:https://doi.org/10.3390/catal 10080843.

32. Dinjus E, Kruse A, Tröger N. Hydrothermal carbonization - 1. Influence of lignin in lignocelluloses. Chemical Engineering and Technology. 2011;34:2037-43. doi:https://doi.org/10.1002/ceat. 201100487

33. Hoffmann, V., Jung, D., Zimmermann, J., Rodriguez Correa, C., Elleuch, A., Halouani, K., Kruse, A.: Conductive carbon materials from the hydrothermal carbonization of vineyard residues for the application in Electrochemical Double-Layer Capacitors (EDLCs) and Direct Carbon Fuel Cells (DCFCs). Materials (Basel) (2019). https://doi.org/10.3390/ma12101703

34. Evcil, T., Simsir, H., Ucar, S., Tekin, K., Karagoz, S.: Hydrothermal carbonization of lignocellulosic biomass and effects of combined Lewis and Brønsted acid catalysts. Fuel 279, 118458 (2020). https://doi.org/10.1016/j.fuel.2020.118458

35. Enaime, G., Baçaoui, A., Yaacoubi, A., Wichern, M., Lübken, M.: Hydrothermal carbonization of the filter bed remained after filtration of olive mill wastewater on olive stones for biofuel application. Biomass Conv. Bioref. (2020). https://doi.org/10. 1007/s13399-020-00743-9

36. Poerschmann, J., Koehler, R., Weiner, B.: Identification and quantification of 2,5-diketopiperazine platform biochemicals along with pyrazines and pyridinols in the dissolved organic matter phase after hydrothermal carbonization of brewer's spent grain. Environ. Technol. Innov. 5, 95-105 (2016). https://doi.org/ 10.1016/j.eti.2016.01.003

37. Depraetere SA, Delvaux F, Coghe S, Delvaux FR. Wheat Variety and Barley Malt Properties: Influence on Haze Intensity and Foam Stability of Wheat Beer. J Institute Brewing. 2004:200-6.

38. Hill, A., Stewart, G.: Free amino nitrogen in brewing. Fermentation. 5, 22 (2019). https://doi.org/10.3390/fermentation5010022

39. Hardwick WA, editor. Handbook of Brewing: Brewery By-Products and Effluents; 1994.

40. Hudson BJF, editor. Biochemistry of food proteins: The maillard reaction; 1992.
41. Hodge, J.E.: Dehydrated foods, chemistry of browning reactions in model systems. J. Agric. Food Chem. 1, 928-943 (1953). https://doi.org/10.1021/jf60015a004

42. van Soest, P.J., Robertson, J.B., Lewis, B.A.: Methods for dietary fiber, neutral detergent fiber, and nonstarch polysaccharides in relation to animal nutrition. J. Dairy Sci. 74, 3583-3597 (1991). https://doi.org/10.3168/jds.S0022-0302(91)78551-2

43. Bradford, M.M.: A rapid and sensitive method for the quantitation of microgram quantities of protein utilizing the principle of protein-dye binding. Anal Biochem. 72, 248-254 (1976). https:// doi.org/10.1006/abio.1976.9999

44. VO (EG) 152/2009. CELEX_32009R0152_DE_TXT.

45. Ohwaki, T., Ishida, H.: Comparison between FT-IR and XPS characterization of carbon fiber surfaces. The J. of Adhesion. 52, 167-186 (1995). https://doi.org/10.1080/00218469508015192

46. Channiwala, S.A., Parikh, P.P.: A unified correlation for estimating HHV of solid, liquid and gaseous fuels. Fuel 81, 1051-1063 (2002). https://doi.org/10.1016/S0016-2361(01)00131-4

47. Kruse, A., Dahmen, N.: Water - A magic solvent for biomass conversion. J. Supercrit. Fluids 96, 36-45 (2015). https://doi.org/ 10.1016/j.supflu.2014.09.038

48. Simsir, H., Eltugral, N., Karagoz, S.: Effects of acidic and alkaline metal triflates on the hydrothermal carbonization of glucose and cellulose. Energy Fuels. 33, 7473-7479 (2019). https://doi. org/10.1021/acs.energyfuels.9b01750

49. Wu, M.J., Clarke, F.M., Rogers, P.J., Young, P., Sales, N., O'Doherty, P.J., Higgins, V.J.: Identification of a protein with antioxidant activity that is important for the protection against beer ageing. Int J Mol Sci. 12, 6089-6103 (2011). https://doi.org/ 10.3390/ijms12096089

50. Wüst, D., Rodriguez Correa, C., Suwelack, K.U., Köhler, H., Kruse, A.: Hydrothermal carbonization of dry toilet residues as an added-value strategy - Investigation of process parameters. J Environ Manage. 234, 537-545 (2019). https://doi.org/10.1016/j. jenvman.2019.01.005

51. Leng, S., Leng, L., Chen, L., Chen, J., Chen, J., Zhou, W.: The effect of aqueous phase recirculation on hydrothermal liquefaction/carbonization of biomass: A review. Bioresour Technol. 318, 124081 (2020). https://doi.org/10.1016/j.biortech.2020.124081

52. Kang, S., Li, X., Fan, J., Chang, J.: Characterization of hydrochars produced by hydrothermal carbonization of lignin, cellulose, d -Xylose, and wood meal. Ind. Eng. Chem. Res. 51, 9023-9031 (2012). https://doi.org/10.1021/ie300565d

53. Keiluweit, M., Nico, P.S., Johnson, M.G., Kleber, M.: Dynamic molecular structure of plant biomass-derived black carbon (biochar). Environ. Sci. Technol. 44, 1247-1253 (2010). https://doi. org/10.1021/es9031419

54. Yang, H., Wang, G., Ding, N., Yin, C., Chen, Y.: Size-controllable synthesis of carbon spheres with assistance of metal ions. Synth. Met. 214, 1-4 (2016). https://doi.org/10.1016/j.synthmet. 2016.01.011

55. Zhou, Q., Gao, Q., Luo, W., Yan, C., Ji, Z., Duan, P.: One-step synthesis of amino-functionalized attapulgite clay nanoparticles adsorbent by hydrothermal carbonization of chitosan for removal of methylene blue from wastewater (2015). https://doi.org/10. 1016/J.COLSURFA.2015.01.092

56. Ombaka, L.M., Ndungu, P.G., Nyamori, V.O.: Pyrrolic nitrogendoped carbon nanotubes: physicochemical properties, interactions with $\mathrm{Pd}$ and their role in the selective hydrogenation of nitrobenzophenone. RSC Adv. 5, 109-122 (2014). https://doi. org/10.1039/C4RA12523A

57. Zhu, Y., Wei, J., Liu, Y., Liu, X., Li, J., Zhang, J.: Assessing the effect on the generation of environmentally persistent free radicals in hydrothermal carbonization of sewage sludge. Sci Rep. 9, 17092 (2019). https://doi.org/10.1038/s41598-019-53781-3 
58. Elaigwu, S.E., Greenway, G.M.: Chemical, structural and energy properties of hydrochars from microwave-assisted hydrothermal carbonization of glucose. Int J Ind Chem. 7, 449-456 (2016). https://doi.org/10.1007/s40090-016-0081-0

59. Jiang, E., Cheng, S., Tu, R., He, Z., Jia, Z., Long, X., et al.: High yield self-nitrogen-oxygen doped hydrochar derived from microalgae carbonization in bio-oil: Properties and potential applications. Bioresour Technol. 314, 123735 (2020). https://doi.org/10. 1016/j.biortech.2020.123735

60. Hoffmann, V., Jung, D., Zimmermann, J., Correa, C.R., Elleuch, A., Halouani, K., Kruse, A.: Conductive carbon materials from the hydrothermal carbonization of vineyard residues for the application in electrochemical double-layer capacitors (EDLCs) and direct carbon fuel cells (DCFCs). Materials (2019). https:// doi.org/10.3390/MA12101703

61. Abdelmoez, W., Nakahasi, T., Yoshida, H.: Amino acid transformation and decomposition in saturated subcritical water conditions. Ind. Eng. Chem. Res. 46, 5286-5294 (2007). https://doi. org/10.1021/ie070151b

62. Hemmler, D., Roullier-Gall, C., Marshall, J.W., Rychlik, M., Taylor, A.J., Schmitt-Kopplin, P.: Evolution of Complex Maillard Chemical Reactions. Resolved in Time. Sci Rep. 7, 3227 (2017). https://doi.org/10.1038/s41598-017-03691-z

63. Lucian, M., Volpe, M., Gao, L., Piro, G., Goldfarb, J.L., Fiori, L.: Impact of hydrothermal carbonization conditions on the formation of hydrochars and secondary chars from the organic fraction of municipal solid waste. Fuel 233, 257-268 (2018). https://doi. org/10.1016/j.fuel.2018.06.060

64. Martins, S.I.F.S., Jongen, W.M.F., van Boekel, M.A.J.S.: A review of Maillard reaction in food and implications to kinetic modelling. Trends Food Sci. Technol. 11, 364-373 (2000). https://doi.org/10.1016/S0924-2244(01)00022-X

65. Kruse, A., Dahmen, N.: Water ? A magic solvent for biomass conversion. The Journal of Supercritical Fluids. 96, 36-45 (2015). https://doi.org/10.1016/j.supflu.2014.09.038

66. Kruse, A., Dinjus, E.: Hot compressed water as reaction medium and reactant. J. Supercritical Fluids. 39, 362-380 (2007). https://doi.org/10.1016/j.supflu.2006.03.016

67. Déniel, M., Haarlemmer, G., Roubaud, A., Weiss-Hortala, E., Fages, J.: Energy valorisation of food processing residues and model compounds by hydrothermal liquefaction. Renew. Sustain. Energy Rev. 54, 1632-1652 (2016). https://doi.org/10. 1016/j.rser.2015.10.017

68. Kruse, A., Bernolle, P., Dahmen, N., Dinjus, E., Maniam, P.: Hydrothermal gasification of biomass: Consecutive reactions to long-living intermediates. Energy Environ. Sci. 3, 136-143 (2010). https://doi.org/10.1039/b915034j

69. Kröger, M., Hartmann, F., Klemm, M.: Hydrothermal treatment of carboxy-methyl cellulose salt: formation and decomposition of furans, pentenes and benzenes. Chem. Eng. Technol. 36, 287-294 (2013). https://doi.org/10.1002/ceat.201200468

70. Déniel, M., Haarlemmer, G., Roubaud, A., Weiss-Hortala, E., Fages, J.: Hydrothermal liquefaction of blackcurrant pomace and model molecules: understanding of reaction mechanisms. Sustainable Energy Fuels. 1, 555-582 (2017). https://doi.org/ 10.1039/C6SE00065G

71. Deters F, Hofmann T, Schieberle P. Influence of High Hydrostatic Pressure on the Formation of Key Maillard-type Flavour Compounds from D-glucose and L-proline. In: Winter R, editor. Advances in High Pressure Bioscience and Biotechnology II: Proceedings of the 2nd International Conference on High Pressure Bioscience and Biotechnology, Dortmund, September 16-19, 2002. Berlin: Springer Berlin Heidelberg; 2003. p. 347-350. doi:https://doi.org/10.1007/978-3-662-05613-4_ 60.
72. Williams, D.L., Dunlop, A.P.: Kinetics of furfural destruction in acidic aqueous media. Ind. Eng. Chem. 40, 239-241 (1948). https://doi.org/10.1021/ie50458a012

73. Kruse, A., Meier, D., Rimbrecht, P., Schacht, M.: Gasification of pyrocatechol in supercritical water in the presence of potassium hydroxide. Ind. Eng. Chem. Res. 39, 4842-4848 (2000). https:// doi.org/10.1021/ie0001570

74. Kruse, A.: Supercritical water gasification. Biofuels, Bioprod. Biorefin. 2, 415-437 (2008). https://doi.org/10.1002/bbb.93

75. Albuquerque, E.M., Borges, L.E.P., Fraga, M.A.: Lactic acid production from aqueous-phase selective oxidation of hydroxyacetone. J. Mol. Catal. A: Chem. 400, 64-70 (2015). https://doi. org/10.1016/j.molcata.2015.02.005

76. Kruse, A., Gawlik, A.: Biomass conversion in water at 330 $410{ }^{\circ} \mathrm{C}$ and $30-50 \mathrm{MPa}$ identification of key compounds for indicating different chemical reaction pathways. Ind. Eng. Chem. Res. 42, 267-279 (2003). https://doi.org/10.1021/ie0202773

77. Akgül, G., Kruse, A.: Hydrothermal disproportionation of formaldehyde at subcritical conditions. J. Supercritical Fluids. 73, 43-50 (2013). https://doi.org/10.1016/j.supflu.2012.11.007

78. Flannelly, T., Lopes, M., Kupiainen, L., Dooley, S., Leahy, J.J.: Non-stoichiometric formation of formic and levulinic acids from the hydrolysis of biomass derived hexose carbohydrates. RSC Adv. 6, 5797-5804 (2016). https://doi.org/10.1039/C5RA2 5172A

79. Reiche, S., Kowalew, N., Schlögl, R.: Influence of synthesis pH and oxidative strength of the catalyzing acid on the morphology and chemical structure of hydrothermal carbon. ChemPhysChem 16, 579-587 (2015). https://doi.org/10.1002/cphc.201402834

80. van Zandvoort, I., Wang, Y., Rasrendra, C.B., van Eck, E.R.H., Bruijnincx, P.C.A., Heeres, H.J., Weckhuysen, B.M.: Formation, molecular structure, and morphology of humins in biomass conversion: influence of feedstock and processing conditions. Chemsuschem 6, 1745-1758 (2013). https://doi.org/10.1002/ cssc. 201300332

81. Aydıncak, K., Yumak, T., Sınağ, A., Esen, B.: Synthesis and characterization of carbonaceous materials from saccharides (glucose and lactose) and two waste biomasses by hydrothermal carbonization. Ind. Eng. Chem. Res. 51, 9145-9152 (2012). https://doi.org/10.1021/ie301236h

82. Luijkx, G.C.A., van Rantwijk, F., van Bekkum, H.: Hydrothermal formation of 1,2,4-benzenetriol from 5-hydroxymethyl-2-furaldehyde and d-fructose. Carbohyd. Res. 242, 131-139 (1993). https://doi.org/10.1016/0008-6215(93)80027-C

83. Hu, J., Shen, D., Wu, S., Zhang, H., Xiao, R.: Effect of temperature on structure evolution in char from hydrothermal degradation of lignin. J. Anal. Appl. Pyrol. 106, 118-124 (2014). https:// doi.org/10.1016/j.jaap.2014.01.008

84. Barbier, J., Charon, N., Dupassieux, N., Loppinet-Serani, A., Mahé, L., Ponthus, J., et al.: Hydrothermal conversion of lignin compounds. A detailed study of fragmentation and condensation reaction pathways. Biomass Bioenerg. 46, 479-491 (2012). https://doi.org/10.1016/j.biombioe.2012.07.011

85. Dinjus, E., Kruse, A., Tröger, N.: Hydrothermal carbonization - 1 Influence of lignin in lignocelluloses. Chem. Eng. Technol. 34, 2037-2043 (2011). https://doi.org/10.1002/ceat.201100487

86. Poerschmann, J., Weiner, B., Koehler, R., Kopinke, F.-D.: Organic breakdown products resulting from hydrothermal carbonization of brewer's spent grain. Chemosphere 131, 71-77 (2015). https://doi.org/10.1016/j.chemosphere.2015.02.057

87. Poerschmann, J., Górecki, T.: Characterization of the Lipid Soluble Fraction of Brewer';s Spent Grain. CCHG. 3, 86-98 (2016). https://doi.org/10.2174/2213240603999160719124953

88. Gillet, S., Aguedo, M., Petitjean, L., Morais, A.R.C., da Costa Lopes, A.M., Łukasik, R.M., Anastas, P.T.: Lignin transformations for high value applications: towards targeted modifications 
using green chemistry. Green Chem. 19, 4200-4233 (2017). https://doi.org/10.1039/C7GC01479A

89. Weide, T., Brügging, E., Wetter, C.: Anaerobic and aerobic degradation of wastewater from hydrothermal carbonization (HTC) in a continuous, three-stage and semi-industrial system. J. Environ. Chem. Eng. 7, 102912 (2019). https://doi.org/10.1016/j.jece. 2019.102912

90. Ryu, J., Suh, Y.-W., Suh, D.J., Ahn, D., J. A.: Hydrothermal preparation of carbon microspheres from mono-saccharides and phenolic compounds. Carbon 48, 1990-1998 (2010)

91. Koch H, Pein J. Condensation reactions between phenol, formaldehyde and 5-hydroxymethylfurfural, formed as intermediate in the acid catalyzed dehydration of starchy products. Polymer Bulletin. 1985:525-32.

92. Jung, D., Zimmermann, M., Kruse, A.: Hydrothermal carbonization of fructose: growth mechanism and kinetic model. ACS Sustainable Chem. Eng. (2018). https://doi.org/10.1021/acssu schemeng. $8 \mathrm{~b} 02118$

93. Peterson, A.A., Lachance, R.P., Tester, J.W.: Kinetic evidence of the maillard reaction in hydrothermal biomass processing: glucose-glycine interactions in high-temperature. High-Pressure Water. Ind. Eng. Chem. Res. 49, 2107-2117 (2010). https://doi. org/10.1021/ie9014809

94. Kim, J.-S., Lee, Y.-S.: The effect of $\mathrm{pH}$ on the formation of furfural compounds in the glucose and fructose with amino acid enantiomers in maillard reaction. JFN. 13, 54-59 (2008). https:// doi.org/10.3746/jfn.2008.13.1.054

95. Abdelmoez, W., Yoshida, H.: Production of amino and organic acids from protein using sub-critical water technology. Int. J. Chem. Reactor Eng. 11, 369-384 (2013). https://doi.org/10.1515/ ijcre-2013-0017

96. Abdelmoez W, Yoshida H, Nakahasi T. Pathways of amino acid transformation and decomposition in saturated subcritical water conditions. 2010.

97. Sato, N., Quitain, A.T., Kang, K., Daimon, H., Fujie, K.: Reaction kinetics of amino acid decomposition in high-temperature and high-pressure water. Ind. Eng. Chem. Res. 43, 3217-3222 (2004). https://doi.org/10.1021/ie020733n

98. Yoshida, H., Tavakoli, O.: Sub-critical water hydrolysis treatment for waste squid entrails and production of amino acids, organic acids, and fatty acids. J. Chem. Eng. Japan / JCEJ. 37, 253-260 (2004). https://doi.org/10.1252/jcej.37.253

99. Yoshida, Terashima, Takahashi. Production of organic acids and amino acids from fish meat by sub-critical water hydrolysis. Biotechnol Prog. 1999;15:1090-4. doi:https://doi.org/10.1021/bp990 0920.

100. Ravber, M.: Hydrothermal degradation of fats, carbohydrates and proteins in sunflower seeds after treatment with subcritical water. Chem. Biochem. Eng. Q. 29, 351-355 (2015). https://doi.org/10. 15255/CABEQ.2015.2193

101. Tressl, R., Nittka, C., Kersten, E., Rewicki, D.: Formation of Isoleucine-Specific Maillard Products from [1-13C]-D-Glucose and [1-13C]-D-Fructose. J. Agric. Food Chem. 43, 1163-1169 (1995). https://doi.org/10.1021/jf00053a009

102. Berger, R.G.: Flavours and fragrances: Chemistry, bioprocessing and sustainability. Springer, Berlin, Heidelberg (2007)

103. Rizzi, G.P.: The strecker degradation of amino acids: newer avenues for flavor formation. Food Rev. Intl. 24, 416-435 (2008). https://doi.org/10.1080/87559120802306058

104. Yaylayan, V.A.: Recent advances in the chemistry of strecker degradation and amadori rearrangement: implications to aroma and color formation. FSTR. 9, 1-6 (2003). https://doi.org/10. 3136/fstr.9.1

105. Zhan, H., Zhuang, X., Song, Y., Yin, X., Wu, C.: Insights into the evolution of fuel-N to NO precursors during pyrolysis of $\mathrm{N}$-rich nonlignocellulosic biomass. Appl. Energy 219, 20-33 (2018). https://doi.org/10.1016/j.apenergy.2018.03.015

106. Matayeva, A., Bianchi, D., Chiaberge, S., Cavani, F., Basile, F.: Elucidation of reaction pathways of nitrogenous species by hydrothermal liquefaction process of model compounds. Fuel 240, 169-178 (2019). https://doi.org/10.1016/j.fuel.2018.11.136

107. Déniel, M., Haarlemmer, G., Roubaud, A., Weiss-Hortala, E., Fages, J.: Bio-oil production from food processing residues: improving the bio-oil yield and quality by aqueous phase recycle in hydrothermal liquefaction of blackcurrant (Ribes nigrum L.) Pomace. Energy Fuels. 30, 4895-4904 (2016). https://doi.org/ 10.1021/acs.energyfuels.6b00441

108. Changi, S.M., Faeth, J.L., Mo, N., Savage, P.E.: Hydrothermal reactions of biomolecules relevant for microalgae liquefaction. Ind. Eng. Chem. Res. 54, 11733-11758 (2015). https://doi.org/ 10.1021/acs.iecr.5b02771

109. Hofmann, T., Schieberle, P.: 2-Oxopropanal, hydroxy-2-propanone, and 1-pyrrolineimportant intermediates in the generation of the roast-smelling food flavor compounds 2-acetyl-1-pyrroline and 2-acetyltetrahydropyridine. J. Agric. Food Chem. 46, 22702277 (1998). https://doi.org/10.1021/jf970990g

110. Cremer, D.R., Vollenbroeker, M., Eichner, K.: Investigation of the formation of Strecker aldehydes from the reaction of Amadori rearrangement products with $\alpha$-amino acids in low moisture model systems. Eur. Food Res. Technol. 211, 400-403 (2000). https://doi.org/10.1007/s002170000196

111. Belitz, H.-D., Grosch, W., Schieberle, P. (eds.): Food chemistry, 4th edn. Springer, Berlin (2009)

112. Na Jom, K., Jamnong, P., Lertsiri, S.: Investigation of acrylamide in curries made from coconut milk. Food Chem Toxicol. 46, 119-124 (2008). https://doi.org/10.1016/j.fct.2007.07.006

113. Stadler, R.H., Verzegnassi, L., Varga, N., Grigorov, M., Studer, A., Riediker, S., Schilter, B.: Formation of vinylogous compounds in model Maillard reaction systems. Chem Res Toxicol. 16, 1242-1250 (2003). https://doi.org/10.1021/tx034088g

114. Heilmann, S.M., Jader, L.R., Sadowsky, M.J., Schendel, F.J., von Keitz, M.G., Valentas, K.J.: Hydrothermal carbonization of distiller's grains. Biomass Bioenerg. 35, 2526-2533 (2011). https:// doi.org/10.1016/j.biombioe.2011.02.022

115. King, J.W., Holliday, R.L., List, G.R.: Hydrolysis of soybean oil. Green Chem. 1, 261-264 (1999). https://doi.org/10.1039/a9088 $61 \mathrm{j}$

116. Tavakoli, O., Yoshida, H.: Squid oil and fat production from squid wastes using subcritical water hydrolysis: free fatty acids and transesterification. Ind. Eng. Chem. Res. 45, 5675-5680 (2006). https://doi.org/10.1021/ie0513806

117. Choura, M., Belgacem, N.M., Gandini, A.: Acid-catalyzed polycondensation of furfuryl alcohol: mechanisms of chromophore formation and cross-linking. Macromolecules 29, 3839-3850 (1996). https://doi.org/10.1021/ma951522f

118. Watanabe, M., Iida, T., Inomata, H.: Decomposition of a long chain saturated fatty acid with some additives in hot compressed water. Energy Convers. Manage. 47, 3344-3350 (2006). https:// doi.org/10.1016/j.enconman.2006.01.009

119. Wang, F., Wang, J., Gu, C., Han, Y., Zan, S., Wu, S.: Effects of process water recirculation on solid and liquid products from hydrothermal carbonization of Laminaria. Bioresour Technol. 292, 121996 (2019). https://doi.org/10.1016/j.biortech.2019. 121996

120. Weiner, B., Poerschmann, J., Wedwitschka, H., Koehler, R., Kopinke, F.-D.: Influence of process water reuse on the hydrothermal carbonization of paper. ACS Sustainable Chem. Eng. 2, 2165-2171 (2014). https://doi.org/10.1021/sc500348v

121. Grein, B., Huffer, M., Scheller, G., Schreier, P.: 4-Hydroxy-2-alkenals and other products formed by water-mediated oxidative decomposition of alpha, beta-unsaturated aldehydes. J. Agric. 
Food Chem. 41, 2385-2390 (1993). https://doi.org/10.1021/jf000 $36 \mathrm{a} 032$

122. Smith, A.M., Singh, S., Ross, A.B.: Fate of inorganic material during hydrothermal carbonisation of biomass: Influence of feedstock on combustion behaviour of hydrochar. Fuel (2016). https:// doi.org/10.1016/j.fuel.2015.12.006

123. Wang, T., Zhai, Y., Zhu, Y., Gan, X., Zheng, L., Peng, C., et al.: Evaluation of the clean characteristics and combustion behavior of hydrochar derived from food waste towards solid biofuel production. Bioresour Technol. 266, 275-283 (2018). https://doi. org/10.1016/j.biortech.2018.06.093

124. Sumaraj, Padhye, L.P.: Influence of surface chemistry of carbon materials on their interactions with inorganic nitrogen contaminants in soil and water. Chemosphere 184, 532-547 (2017). https://doi.org/10.1016/j.chemosphere.2017.06.021

Publisher's Note Springer Nature remains neutral with regard to jurisdictional claims in published maps and institutional affiliations.

\title{
Authors and Affiliations
}

\author{
Wüst Dominik ${ }^{1,2}$ D Arauzo Pablo ${ }^{2} \cdot$ Habicht Sonja $^{3} \cdot$ Cazaña Fernando $^{4} \cdot$ Fiori Luca ${ }^{1} \cdot$ Kruse Andrea $^{2}$ \\ Wüst Dominik \\ Dominik.Wust@unitn.it \\ 3 Institute for Catalysis Research and Technology, \\ Hermann-von-Helmholtz-Platz 1, \\ 73760 Leopoldshafen-Eggenstein, Germany
}

1 Department of Civil, Environmental and Mechanical Engineering, University of Trento, via Mesiano 77, 38123 Trento, Italy

2 Present Address: Department of Conversion Technologies of Biobased Resources, Institute of Agricultural Engineering, University of Hohenheim, Garbenstrasse 9, 70599 Stuttgart, Germany
4 Department of Chemical Engineering, Aragon Institute of Nanoscience (INA), University of Zaragoza, Campus Río Ebro-Edificio I+D, c/ Poeta Mariano Esquillor s/n, 50018 Zaragoza, Spain 